\title{
Competence in endosonographic techniques
}

\author{
Piero CANDOLI 1 *, Loris CERON 2 , Rocco TRISOLINI ${ }^{3,4}$, Micaela ROMAGNOLI 5 , \\ Lucio MICHIELETTO ${ }^{6}$, Simone SCARLATA ${ }^{4}$, Thomas GALASSO ${ }^{1}$, Fausto LEONCINI 7 , Valeria PASINI ${ }^{8}$, \\ Donatella DENNETTA ${ }^{9}$, Francesca MARCHESANI ${ }^{10}$, Mariagioconda ZOTTI ${ }^{11}$, Lorenzo CORBETTA 12
}

1UOC Pneumologia, Azienda Ospedali Riuniti Marche Nord, Pesaro, Pesaro-Urbino, Italy; 2 UO Pneumologia, Ospedale dell'Angelo, Mestre, Venice, Italy; ${ }^{3} \mathrm{OOC}$ Pneumologia Interventistica Metropolitana, Policlinico Sant'Orsola e Ospedale Maggiore, Bologna, Italy; ${ }^{4}$ UOC Pneumologia Interventistica, Policlinico Sant'Orsola-Malpighi, Bologna, Italy; ${ }^{2}$ UOC di Gerontologia, Policlinico Universitario Campus Bio-Medico di Roma, Rome, Italy; ${ }^{6}$ UOC Pneumologia, Azienda Ospedali Riuniti Marche Nord, Pesaro, Pesaro-Urbino, Italy; ${ }^{7}$ Malattie dell'Apparato Respiratorio AOU Careggi, Florence, Italy; ${ }^{8}$ Interventional Pulmonary Program, University of Florence, Florence, Italy; ${ }^{9}$ Azienda Ospedaliera Ospedali Riuniti Marche Nord, UO Pneumologia, Ospedale San Salvatore, Pesaro, Pesaro-Urbino, Italy; ${ }^{10}$ OUC Pneumologia, Ospedale Macerata, ASUR, Macerata, Italy; 11 Ospedale Santa Maria Goretti UOSD Pneumologia, Latina, Italy; ${ }^{12}$ Università degli Studi di Firenze, SOD Pneumologia Interventistica AOUC, Florence, Italy

*Corresponding author: Piero Candoli, UOC Pneumologia, Azienda Ospedali Riuniti Marche Nord, Pesaro, Pesaro-Urbino, Italy. E-mail: pcandoli@libero.it A B S T R A C T
Endobronchial ultrasound (EBUS) has revolutionized the field of bronchoscopy because it allows to observe peribronchial structures and distal
peripheral lung lesions. The use of EBUS was first described by Hurte and Hanrath in 1992. EBUS technology exists in two forms: radial and
convex transducer probes. The radial EBUS probe has a 20-MHZ (12-30 MHz available) rotating transducer that can be inserted together with
or without a guide sheath through the working channel (2.0-2.8 mm) of a standard flexible bronchoscope. The transducer rotates and produces
a 360 -degree circular image around the central position of the probe. There are two types of radial EBUS probes: "peripheral" probes, used to
identify parenchymal lung lesions, and "central" probes, with balloon sheaths, used for the assessment of airway walls and peribronchial lymph
nodes.
(Cite this article as: Candoli P, Ceron L, Trisolini R, Romagnoli M, Michieletto L, Scarlata S, et al. Competence in endosonographic techniques.
Panminerva Med 2019;61:249-79. DOI: 10.23736/S0031-0808.18.03570-X)
KEY wORD: Bronchoscopy - Training - EBUS - Interventional Pulmonology.

E ndobronchial ultrasound (EBUS) has revolutionized the field of bronchoscopy because it allows to observe peribronchial structures and distal peripheral lung lesions. The use of EBUS was first described by Hurte and Hanrath in $1992.1^{1}$ EBUS technology exists in two forms: radial and convex transducer probes. The radial EBUS probe has a 20-MHZ (12-30 MHz available) rotating transducer that can be inserted together with or without a guide sheath through the working channel (2.0-2.8 $\mathrm{mm}$ ) of a standard flexible bronchoscope. The transducer rotates and produces a 360-degree circular image around the central position of the probe. There are two types of radial EBUS probes: "peripheral" probes, used to identify parenchymal lung lesions, and "central" probes, with bal- loon sheaths, used for the assessment of airway walls and peribronchial lymph nodes. ${ }^{2}$

The convex EBUS probe is a flexible bronchoscope with a convex ultrasound probe at its tip that enables the sampling of lymph nodes adjacent to the airway under real-time ultrasound guidance. This EBUS bronchoscope has an external diameter of $6.9 \mathrm{~mm}$, larger than a standard flexible bronchoscope. Usually, endobronchial examination is limited because of the restricted and oblique endoscopic view, and so a standard bronchoscopy may be needed for a complete airway examination. The $5-15 \mathrm{MHz}$ EBUS transducer is convex and offers a scanning depth of up to $12 \mathrm{~cm}$ and a scanning range of $60^{\circ}$. A disposable latex balloon can be placed over the transducer and can 
be inflated with normal saline through a special balloon channel inside the scope. The echo-bronchoscope has a 2.0 working channel that allows the entry of the aspiration needle. The needle has an internal diameter equivalent to $21,22,25$ and $19 \mathrm{G}$ and the depth of penetration can vary between 5 and $40 \mathrm{~mm}$ with a safety lock. After endobronchial intubation, the EBUS-TBNA scope is positioned at the approximate location of the target lymph node or paratracheal tumor. Simultaneous imaging of the endoscopic and ultrasound views, as well as a detailed knowledge of mediastinal anatomy facilitate the identification of target lesions. Once the target lymph nodes or tumor are identified, real-time TBNA is performed. Most mediastinal and hilar lymph nodes are accessible with EBUS -TBNA bronchoscope except for the aorto-pulmonary (station 5), subaortic (station 6), paraesophageal (station 8) and pulmonary ligament (station 9) nodes. For mediastinal staging of non-small cell lung cancer, three cytology aspirations of lymph node stations are recommended, if an adequate core specimen is obtained, then two passes will enough. ${ }^{3}$

Real-time EBUS-TBNA has shown higher diagnostic yield in mediastinal staging than blind TBNA. The diagnostic sensitivity is $90 \%$ and specificity is $100 \%$. Even without the presence of rapid on-site cytology, diagnostic yields of $88-100 \%$ have been reported for real time EBUSTBNA. The endoscopic ultrasound (through the esophagus) with fine needle aspiration EUS-FNA, and the transesophageal and gastric use of the EBUS (EUS-B-FNA) have been performed in the last decade by pulmonologist for the diagnosis and staging of lung cancer and for the diagnosis of benign diseases.

EBUS-TBNA with transesophageal EUS-FNA can complete staging of mediastinum with access to not accessible lymph node stations (station 8 and 9). Diagnostic sensitivities of $93-94 \%$ have been reported with EBUS and EUS combined procedures. ${ }^{4}$

Training to perform EBUS includes knowledge of imagine interpretation, knobology (that is the use of ultrasound processor), orientation of endoscopic and ultrasound views, knowledge of biopsy techniques, thoracic anatomy and basic competence in flexible bronchoscopy/TBNA. ${ }^{2}$ The accuracy of EBUS-TBNA depends on experience. ${ }^{5}$ An EBUS simulator accurately stratifies individuals on the level of experience in performing EBUS. Training achieved on a simulator is comparable to traditional apprentice-based training. Importantly, skills acquired on a simulator could be transferred to real patients. The number of EBUS needed to overcome the initial learning curve varies from 10 to 100 in individual studies with a mean of $37-44$ procedures.
Tools such as EBUS-STAT (EBUS skill and task assessment tool) and EBUSAT (EBUS skill and assessment tool) were effective in evaluating the EBUS trainees. ${ }^{6}$

In summary, trainees need to know about the following subjects:

- anatomy and imaging (CT scan, PET) of mediastinal lymph nodes and correlation with ultrasound bronchoscopy;

- node landmarks for cTBNA and EBUS-TBNA, as well as nodal maps of the International Association for the Study of Lung Cancer (IASLC) guidelines and understand key anatomical relations at each of the seven commonly biopsied sites;

- diagnosis and staging of NSCLC and role of EBUS/ TBNA in the staging algorithm;

- organization of endoscopic suite and knowledge of the equipment for the performance of EBUS/TBNA on patient under moderate and deep sedation;

- strategy of systematic approach and selective approach;

- contraindications and risk/benefit ratio of EBUS/ TBNA, EUS-B-TBNA and EUS/TBNA;

- equipment for EBUS/EUS: ultrasound bronchoscopes, ultrasound machine and different-sized needles;

- physics and principles of ultrasound;

- technique for collecting cytology and histology specimens; types and sizes of needles and guide systems;

- basic knowledge of cytology: technique of rapid staining and reading of slides for a rapid on site evaluation (ROSE);

- alternative sampling methods (i.e. mediastinoscopy);

- risk management, informed consent and medical legal issues.

\section{Knowledge of anatomy of mediastinal lymph nodes}

According to the International Association for the Study of Lung Cancer (IASLC) classification, the hilo-mediastinal lymph node are divided into different lymph node regions 7 delimited from specific anatomic borders. It's essential to know these anatomic borders in order exactly individualize the lymph node stations; moreover it's possible to recognize some of this borders with EBUS/EUS-(B) ultrasound findings, helping in distinguish one lymph node station from the other.

The IASLC map (Figure 1) 7 divides mediastinal lymph nodes into 7 zones: supraclavicular, upper, aortopulmonary, subcarinal, lower, hilar, interlobar and peripheral. These zones are further classified into 14 numbered sta- 


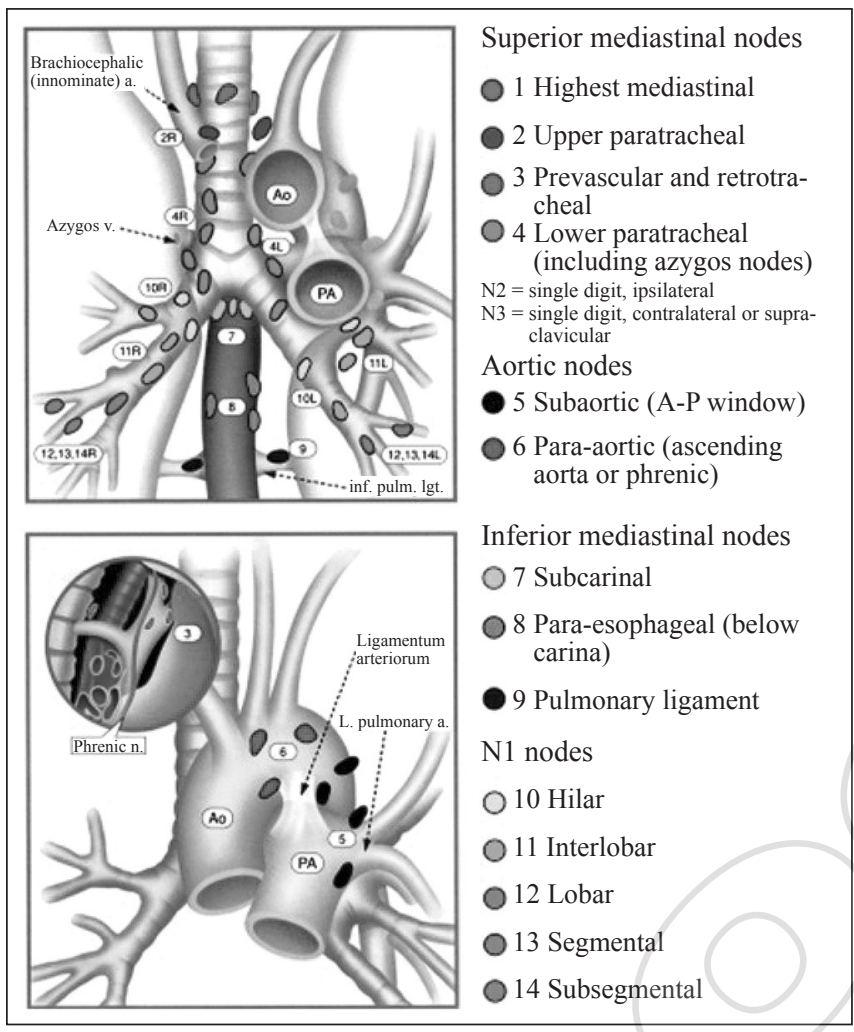

Figure 1.-IASLC map.

tions with the descriptor $\mathrm{R}$ or $\mathrm{L}$ added to denote laterality (R, right; L, left).

To adequately perform, it is mandatory to have a profound knowledge of mediastinal anatomy and be able to correlate it to the ultrasound landmarks (both EBUS and EUS) and the endobronchial specific puncture site.

\section{Knowledges of diseases}

Indications to the procedure

- Staging of non-small-cell lung cancer (NSCLC) according to American College of Chest Physicians (ACCP) guidelines;

- restaging after neoadjuvant treatment;

- diagnosis of mediastinal/hilar nodes in patients with lung masses, either as the first means of making a tissue diagnosis or as the means of staging a known cancer;

- diagnosis of other isolated mediastinal masses;

- confirmation of sarcoidosis in patients with bilateral mediastinal/hilar nodes, either as a sole method or in combination with transbronchial lung biopsy;

- tumor near esophagus and tracheobronchial tree.
Staging of lung cancer

Lung cancer staging is a crucial step in a patient potentially suitable for surgery. In particular, evaluation of mediastinal metastatic spread represents the main prognostic factor, when distant metastasis are not present; 8,9 mediastinal staging is a primary task of the pulmonologist.

ACCP Guidelines on Diagnosis and Management of Lung Cancer, 3th edition, state that a needle technique (endobronchial ultrasound needle aspiration [EBUS-NA], endoscopic ultrasound needle aspiration [EUS-NA] or combined EBUS/EUS-NA) is recommended over surgical staging as a best first test in patients with high suspicion of N2, N3 involvement either by discrete mediastinal lymph node enlargement or PET uptake, when adequate technology and appropriate experience and skill of the operators are available and no distant metastases are present. Moreover, a needle technique is suggested in patients with intermediate suspicion of N2-N3 involvement, i.e. patients with normal mediastinum by CT and PET and central tumor or N1 lymph node enlargement; 10,11 in the latter case, the prevalence of mediastinal involvement was demonstrated to be relevant (up to $23.5 \%$ ), ${ }^{12}$ whereas the indication to invasive mediastinal staging after negative TC and PET in case of central tumors is based on a unique multicenter study that does not separate $\mathrm{cN} 1$ from central tumors. ${ }^{13}$ Likewise, no distinction is made by guidelines either on the basis of tumor histology (squamous vs. adenocarcinoma) or of pleural contact/invasion; most literature contributions report a higher mediastinal involvement rate in adenocarcinoma than in squamous cell carcinoma, ${ }^{14-17}$ and in the event of adenocarcinoma with visceral pleural invasion (fissures included). ${ }^{18-20}$ These factors should be taken into account when deciding on endosonographic staging approach.

Even for peripheral tumours $>3 \mathrm{~cm}$ (especially adenocarcinoma with high FDG uptake) and, by some authors, for those with low maximum standard uptake value, 9,21 further mediastinal staging techniques providing histology should be considered. Whilst many evidences support the relationship between a high FDG uptake in the primary tumor and the risk of lymphatic or distant metastatic spread, ${ }^{12,22}$ the risk of occult mediastinal metastasis in case of low SUV value is less convincing or even contradicted by recent works. 23

Several meta-analyses on EUS-FNA alone, EBUS-TBNA alone, and combined EUS+EBUS reported a pooled sensitivity of $83 \%$ to $94 \%$ for mediastinal staging of lung cancer. ${ }^{24-30}$ Only one randomized controlled trial ${ }^{31}$ has been performed, comparing the two staging strategies proposed in the ESTS 2007 guidelines (either mediastinos- 
copy, or alternatively endosonography followed by mediastinoscopy). ${ }^{9}$ There was no difference in sensitivity or NPV when compared with endoscopic staging. However, the staging strategy starting with combined endosonography and if negative combining it with surgical staging has proven to detect significantly more mediastinal nodal N2/N3 disease compared to mediastinoscopy alone. ${ }^{32}$ This strategy has been recently debated; on the basis of the current guidelines, a surgical confirmatory staging procedure should be chosen when the risk of N2-N3 metastasis is considered still high even after a negative cytological result. ${ }^{10}$ The significance of "residual high suspicion" is not clearly specified, however it seems reasonable that for example in case of high FDG PET uptake, a subsequent negative cytology should prompt a surgical confirmation.

Some authors speculate that omitting mediastinoscopy after negative endosonography in mediastinal staging of NSCLC does not result in an unacceptable percentage of unforeseen N2 disease at surgical resection; 33 omitting mediastinoscopy comprises no extra waiting time, omits one extra general anesthesia and hospital admission, and may reduce morbidity and costs, with comparable survival. However, the decision to avoid a surgical confirmation after a negative cytology from endobronchial or endoesophageal needle aspiration should take into consideration the residual probability of mediastinal metastasis after a negative cytology, and suggest direct resort to surgery only when the final probability is below a predefinite threshold; a mathematical model based upon Bayes' theorem was proposed by some authors to get an estimation of the residual probability of mediastinal involvement after every staging procedure. 34

There is evidence coming from prospective studies performed in experienced endosonography centers, that EBUS keeps a high sensitivity and concurrently mediastinoscopy may not improve diagnostic yield after a wellperformed negative endosonography with needle aspiration of at least three mediastinal nodal stations in patients with low $(<35 \%)$ prevalence of mediastinal disease. $2,35,36$ However, in a discordant manner, data from one prospective study published in 2010,373 recent studies ${ }^{38-40}$ among which two retrospective and one prospective, and a metaanalisis ${ }^{41}$ report a low sensitivity in mediastinal staging (respectively $68 \%$ and $35-49 \%$ ) in $\mathrm{cN} 0-1$ patients with negative mediastinum after TC and PET, hence, precisely in case of low prevalence of mediastinal metastasis. Based on these observations, some authors ${ }^{40}$ question whether EBUS is the best choice in patients with resectable cN1 (but also cN0) lung cancer.
These conflicting data require further confirmation with controlled, prospective trials; in the meanwhile, much prudence has to be used when evaluating these results, since many procedural limitation could influence their value.

\section{Mediastinal masses and granulomatosis}

Benign or malignant mediastinal masses can develop from structures that are normally located in the mediastinum, as well as from metastases of malignancies that arise from the lungs, or from other parts of the body.

Mediastinal masses can be an incidental finding in patients who undergo chest radiography or more advanced imaging studies, e.g. computed tomography (CT) or magnetic resonance imaging for other reasons. These investigations may have been obtained prior to elective surgery, e.g. in case of lung cancer, or as part of the evaluation of an unrelated condition. However, more frequently mediastinal masses are symptomatic, in these cases due to malignant lesions. Symptoms, when present, may be caused by the direct mass effect of the mediastinal abnormalities, or systemic effects of the illness, e.g. fever, night sweats, and weight loss can be present in the case of lymphoma, or may be due to a variety of paraneoplastic syndromes, such as myasthenia gravis with thymoma. Direct involvement or compression of normal mediastinal structures cause a wide range of symptoms, e.g. cough, stridor, hemoptysis, shortness of breath, pain, dysphagia, hoarseness, facial and/or upper extremity swelling due to vascular compression (e.g. superior vena cava syndrome), hypotension due to tamponade physiology or cardiac compression, and Horner syndrome due to sympathetic chain involvement. In the suspicion of a mediastinal mass, diagnostic evaluation includes history and physical examination, supplemented by laboratory and imaging studies. Laboratory studies or blood tumor markers might support a specific diagnosis. Concerning imaging, the location of the mass often helps narrowing the differential diagnosis. As an example, the presence of a large anterior mediastinal mass and elevations in certain tumor markers might establish the diagnosis of some germ cell tumors. In other cases, a tissue biopsy (percutaneous, endobronchial, or surgical) may be necessary to confirm a clinical suspicion prior to establishing a therapeutic plan.

CT of the chest with intravenous contrast is typically used to evaluate abnormalities seen on chest radiographs. Chest CT also provides detailed information regarding the mediastinal abnormality, including its location, size, relationship to other structures, and tissue characteristics, including presence of fat, fluid, or calcifications (e.g. 
teratoma). Such detailed information, particularly the involvement or compression of surrounding structures, is important in the treatment approach. When lymphoma is suspected, positron emission tomography (PET) using 18F-fluorodeoxyglucose (FDG) with fused CT may be performed, being useful to identify a preferred biopsy site. It must be highlighted that also non-malignant conditions, such as teratoma and thymic cysts, have shown to have FDG accumulation in $14 \%$ to $42 \%$ of cases. ${ }^{42-44}$

The mediastinum is divided into main three compartments, and this is useful in developing a differential diagnosis when an abnormality is detected: the anterior, middle and posterior compartment. The most common lesions occurring in the anterior mediastinum are represented by thymoma, teratoma/germ cell tumor, lymphoma, and thyroid tissue, whereas in the middle mediastinum is lymphadenopathy, which can be secondary to lymphoma, sarcoid, or metastatic lung cancer. Neurogenic tumors represent the majority of posterior mediastinal masses.

EBUS and/or EUS are reasonable to consider when the mediastinal mass is located mainly in the middle (and posterior) mediastinum, immediately adjacent to an airway or to the esophagus. Lesions in these locations are often difficult to access percutaneously even with radiographic imaging guidance due to the proximity of major vascular structures. There are rather limited data as to the use of EUS-FNA in the diagnosis of mediastinal lymphoproliferative disorders, showing a good sensitivity and specificity, although lower as compared to NSCLC. The combination of EUS-guided FNA \pm flow cytometry (FC) for the diagnosis of lymphomas was initially considered controversial, but some retrospective data showed that EUS-FNA is sensitive and specific for the diagnosis of suspected lymphoma. Confirmatory further testing should be performed when EUS-FNA with or without FC is indeterminate and or non-diagnostic. The overall sensitivity and specificity in the diagnosis of lymphoma is 73 to $87 \%, 87$ to $100 \%$, with a positive predictive value, negative predictive value and accuracy of $97 \%, 60 \%$ to $75 \%$ and $83 \%$ to $89 \%$, respectively. 45,46

For mediastinal masses/lymphadenopathy of unknown origin, the European Society of Gastrointestinal Endoscopy (ESGE) recommends performing EUS-guided (or alternatively EBUS-guided) sampling if the pathological result is likely to affect patient management, and no superficial lymphadenopathy is easily accessible, with strong recommendation, moderate quality evidence. .5

EBUS can visualize and sample mediastinal and hilar lymphadenopathy to distinguish benign from malignant lesions (other than NSCLC). The most common use for convex probe EBUS-TBNA in this setting is in patients with bilateral hilar adenopathy to distinguish sarcoidosis from lymphoma. Although EBUS has been established as an effective modality to diagnose lung cancer, its sensitivity for the diagnosis of lymphoma has been demonstrated to be lower. Because of this lower yield, uncertainty persists about the ability of EBUS-TBNA to reliably diagnose lymphoma and questions remain regarding the utility of EBUS-TBNA as a first-line biopsy modality for patients suspected of having lymphoma. However, some recent data seem to be promising. In a recent report, although the number of patients affected by lymphoma was relatively low (17 patients), the authors showed an overall sensitivity of EBUS-TBNA for lymphoma of $85 \%$, together with an adequate subtyping, allowing treatment recommendations. ${ }^{46}$ Frequently, with the current 21- and 22-gauge (G) EBUS-TBNA needles, the procedure might be limited by the degree of flexibility in the needle and the size of the lumen in tissue acquisition. Recent data with a first-generation flexible 19-G EBUSTBNA needle suggest a successful diagnostic yield also in cases of lymphoma $(100 \%),{ }^{47}$ although the number of lymphoma was small (4 cases). When lymphoma is highly suspected and endobronchial biopsy is not possible or cannot provide adequate tissue to definitively establish a diagnosis, surgical biopsy may be necessary, excisional biopsy of a small mass, if possible, or incisional biopsy of a large mass is preferred, although in select cases large core needle biopsies may be adequate.

In cases of granulomatous diseases, e.g. sarcoidosis (and tuberculosis), several studies have reported a high diagnostic yield of EBUS-TBNA for the diagnosis of sarcoidosis, with a diagnostic yield of EBUS-TBNA of $83.3 \%$ (higher than TBNA 53.8\%, $\mathrm{P}<0.05$ ), a pooled diagnostic accuracy of $79 \%$ (95\% CI $71 \%$ to $86 \%$ ) in a systematic review and meta-analysis, whereas the clinical factors associated with successful demonstration of non-necrotizing granulomatous inflammation in EBUS-TBNA samples have not been clearly established. ${ }^{48-50}$

Concerning EUS-FNA in the diagnosis of sarcoidosis, a study from 101 consecutive patients $(55 \%$ of whom had previously had a non-diagnostic bronchoscopy) with suspected pulmonary sarcoidosis (stage I and II), who underwent EUS-FNA of mediastinal lymph nodes with 22-gauge needles showed that the sensitivity of EUS in detecting granulomas was $87 \%$ (cytology and cell-block analysis together) (stage I, 92\%; stage II, 77\%). In 33\% of cytology negative patients $(\mathrm{N} .=6)$, granulomas were pres- 
ent in the cell block. The optimal yield for granuloma detection was reached with four needle passes. One patient developed mediastinitis after EUS-FNA. ${ }^{51}$

\section{Knowledge of basis of sonography and of the instruments}

Basis of sonography

EBUS is a bronchoscopic technique that uses ultrasound to visualize structures within and around the airway wall as well as the lung.

Sound waves are mechanical vibrations that can be described in terms of frequency or Hertz (Hz), i.e., the number of repetitions or cycles per second.

The sounds heard by humans are between $16 \mathrm{~Hz}$ and 20 KHz. Waves with frequencies above, we define ULTRASOUND.

Medical ultrasound imaging typically uses sound waves at frequencies of $1,000,000$ to $20,000,000 \mathrm{~Hz}$ (1.0 to 20 $\mathrm{MHz}$.

The ultrasound beam is composed of a train of waves generated by piezoelectric effect by a sensor or transducer. To this effect, the electrical energy is converted into mechanical energy and vice versa vibratory.

ECO is an acoustic phenomenon that occurs when a sound meets a "wall" that reflects it; the echo is reflected sound.

Echogenicity represents the extent to which a structure (tissue or substance) gives rise to reflections of ultrasonic waves. When US images are displayed on a grey scale, the strongest echo signal is white. When no sound wave is reflected, the image is black, or, in US terms, anechoic.

Frequency represents a specific number of vibration cycles per second, measured in units of hertz. EBUS frequencies range from 5 to $12 \mathrm{MHz}$. Dedicated convex-probe EBUS-TBNA bronchoscopes allow a change in frequency from 5 to $12 \mathrm{MHz}$, while available high-frequency radial EBUS systems use frequencies of 20-30 MHz.

An US wavelength represents the distance between two successive pulses: the higher the frequency, the shorter the related wavelength. Transducers may serve as both source and sensor of the acoustic signal: they convert electrical signals to US waves and transmit them, and pick up the reflected waves and convert them into electrical signals.

Frequency and wavelength are mathematically related to the velocity of the ultrasound beam within the tissue (approximately 1,540,000 $\mathrm{mm} / \mathrm{sec}$ for human tissue) as indicated by the following equations:

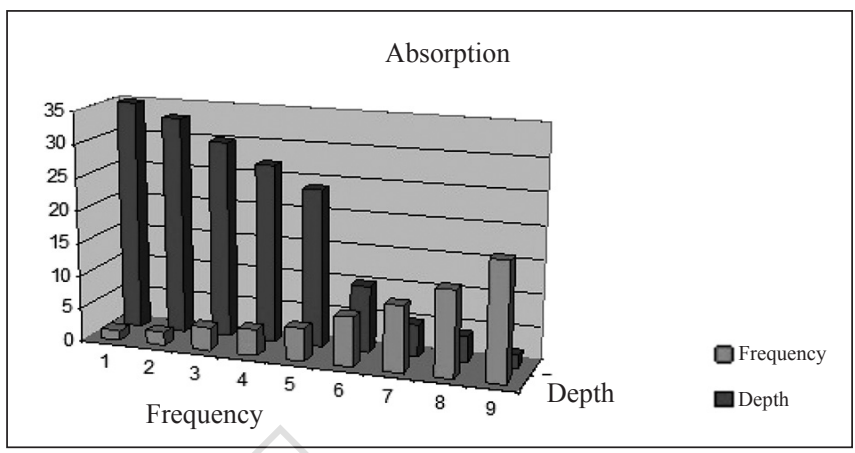

Figure 2.- Ultrasound absorption. High frequency corresponds to a low depth for effect of absorption.

- velocity of blood=Wavelength $(\mathrm{mm}) \mathrm{x}$ frequency $(\mathrm{Hz})$;

- wavelength $(\mathrm{mm})=1,540,000 \mathrm{~mm} / \mathrm{sec} \div$ frequency $(\mathrm{Hz})$;

- wavelength $(\mathrm{mm})=1,54 \div$ frequency $(\mathrm{MHz})$.

The resolution of a recording, ie, the ability to distinguish two objects that are spatially close together, varies directly with the frequency and inversely with the wavelength. High frequency, short wavelength ultrasound can separate objects that are less than $1 \mathrm{~mm}$ apart (Figure 2).

Imaging with higher frequency (and lower wavelength) transducers permits enhanced spatial resolution. However, because of attenuation, the depth of tissue penetration or the ability to transmit sufficient ultrasonic energy into the chest is directly related to wavelength and therefore inversely related to transducer frequency. As a result, the use of higher frequency transducers reduces tissue penetration.

The trade-off between tissue resolution and penetration guides the choice of transducer frequency for clinical imaging.

\section{Propagation, reflection, refraction and attenuation}

Propagation is the process in which sound advances through various substances such as air and water.

The transducer serves as both the source and sensor of a pulsed signal; the signal is sent out, penetrates tissue and is then reflected back to transducer. The intensity of reflection is higher wherever there is a significant change in the propagation medium. The degree of reflection is determined by the acoustic impedance of the adjacent tissue. Acoustic impedance ( $Z=$ density $x$ speed of sound) is related to tissue density.

When the US beam strikes an interface, it undergoes refraction, scattering and attenuation. 


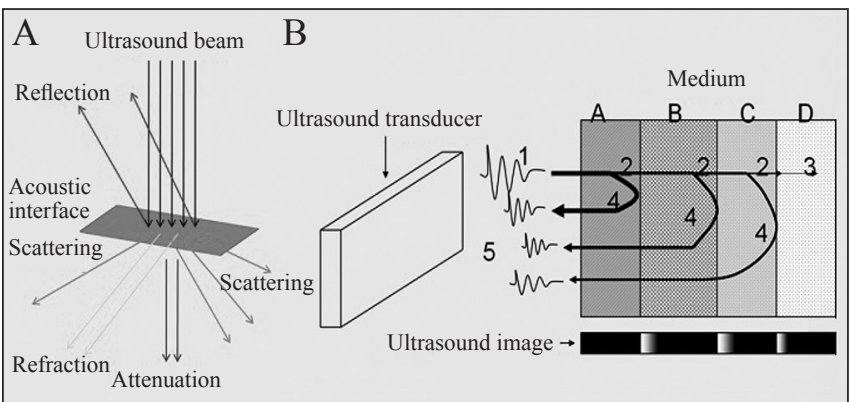

Figure 3.-Principles of ultrasound.

Refraction represents a change in direction of the incident US beam. Scattering is the spread of the US in different directions. Attenuation is loss of energy caused by absorption (Figure 3).

\section{Image artefacts}

We have reverberation artefacts when a highly reflective tissue is parallel to the transducer, or when the balloon of the EBUS probe is not in perfect contact with the airway wall and the acoustic waves are repeatedly/reflected between the airway wall and the transducer. False echoes appear as multiple equally spaced lines on the US image.

In addition to intimate contact between the transducer and the airway wall, image quality adjustments are made using gain, contrast and Doppler functions on the processor.

\section{Gain, Doppler, Color Doppler}

Gain represents the function for adjusting the brightness of the image. When the US waves travel into the tissue, high frequencies components are absorbed more than low frequencies; the loss of amplitude is corrected by amplifying the signal proportional to the depth from which the echo comes. The amplifier is controlled by the operator.

The Doppler effect represents the phenomenon through the frequency of the reflected ultrasound wave is changed when it strikes a moving object (i.e. blood cells within blood vessels).

Color Doppler refers to a color code used to indicate flow direction and velocity.

By convention, the flows approaching the transducer are represented in RED, those moving away in BLUE (Figure 4). In general, the Doppler angle needs to be $60^{\circ}$ or slightly less compared to the long axis of the vessel to obtain the right velocity. If the US scanning plane is perpendicular to the direction of blood flow, it is possible that there will be no Doppler signal.

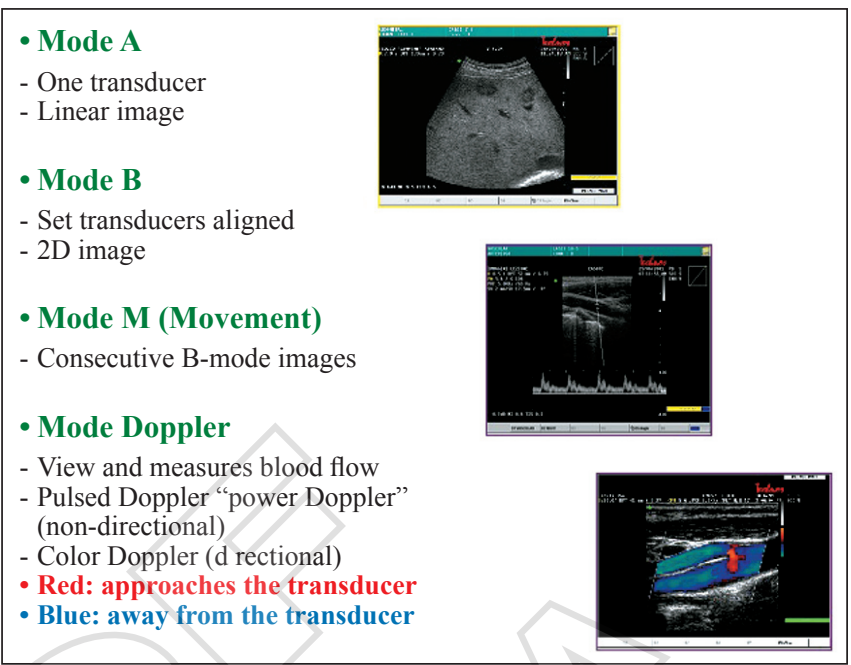

Figure 4.- - Modes of ultrasound in medicine.

\section{Ultrasound imaging}

Ultrasound waves are produced by a transducer, a device that use piezoelectric crystals to both generate and receive ultrasound waves. The transducer converts electrical signals to US waves, pick up the reflected waves and converts them in electrical signals. The electrical signals returned from the transducer form an image on a display panel. Ceramics such as lead-zicornate titanate are commonly used transducers materials.

The crystals deform and vibrate when electronically stimulated to produce acoustic pulses. When echoes return to the transducer distort the crystals and produce an electric pulse that is processed into an image (Figure 5).

Instruments (Transducers and scanning methods)

\section{EBUS}

There are two types of Ultrasound transducers used in bronchoscopy:

- 20 and $30 \mathrm{MHz}$ miniaturized radial transducers that

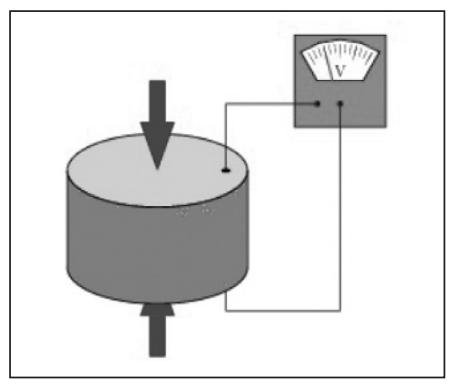

Figure 5.-Piezoelectric effect. 
TABLE I.-Technical characteristics of the different EBUS endoscope.

\begin{tabular}{|c|c|c|c|}
\hline Model & $\begin{array}{l}\text { Pentax } \\
\text { EB19-J10U }\end{array}$ & $\begin{array}{c}\text { Fuji } \\
\text { EB530US }\end{array}$ & $\begin{array}{c}\text { Olympus } \\
\text { BF-UC190F }\end{array}$ \\
\hline $\begin{array}{l}\text { Direction } \\
\text { of viewing field }\end{array}$ & $\begin{array}{c}\text { Forward } \\
\text { oblique }\left[45^{\circ}\right]\end{array}$ & $\begin{array}{c}\text { Forward } \\
\text { oblique }\left[10^{\circ}\right]\end{array}$ & $\begin{array}{c}\text { Forward } \\
\text { oblique }\left[20^{\circ}\right]\end{array}$ \\
\hline Field of view $\left[^{\circ}\right]$ & 100 & 120 & 80 \\
\hline Depth of field [mm] & $2-50$ & $3-100$ & $2-50$ \\
\hline Tip deflection ud/down $\left[{ }^{\circ}\right]$ & $120 / 90$ & $130 / 90$ & $160 / 70$ \\
\hline Insertion tube [Ø mm] & 6.3 & 6.3 & 6.3 \\
\hline Distal end [Ø mm] & 7.3 & 6.7 & 6.6 \\
\hline $\begin{array}{l}\text { Instrument channel [ } \\
\text { mm] }\end{array}$ & 2.2 & 2.0 & 2.2 \\
\hline Working length [Ø mm] & 600 & 610 & 600 \\
\hline Scanning angle $\left[{ }^{\circ}\right]$ & 75 & 65 & 65 \\
\hline Acustic frequency [MHz] & $\begin{array}{l}5,6.5,7.5,10 \\
13 \text { switchable }\end{array}$ & $5,7.5,10,12$ & $\begin{array}{c}5,6,7.5,10, \\
12\end{array}$ \\
\hline Scanning direction & Parallel & Longitudinal & Parallel \\
\hline Scanning system & Convex & Convex & Convex \\
\hline
\end{tabular}

provide a $360^{\circ}$ scanning plane that is perpendicular to the probe axis;

- Convex linear probe.

The Convex-probe linear array (Table I) is comprised of a group of adjacent elements arranged in linear sequence on the transducer. The probe is positioned on the tip of the bronchoscope.

The elements are electrically phased to produce a beams that sweep a $2 \mathrm{D}$ plane in the shape of hand-fan or pie-slice $\left(50-60^{\circ}\right)$, parallel to the axis of the bronchoscope; the electronic beam is focused at selected depth.

The convex probes commercially available have frequency between 5 and $12 \mathrm{MHz}$.

The outer diameter of the scopes have $6.9-7.45 \mathrm{~mm}$ dis-

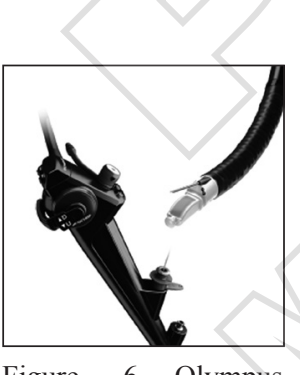

Figure 6.-Olympus Figure 7.-Pentax EB19-J10U. BF-UC190F.
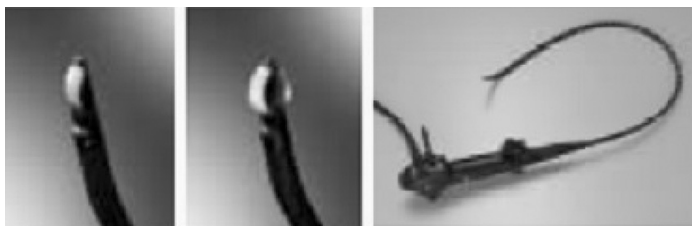

Figure 8.-EB530US tal extremity. The optical visual field of view is $80-100^{\circ}$ and the direction of the white-light viewing axis is $10-45^{\circ}$ forward oblique, depending on the type of the bronchoscope used (Table I). The working channel is between 2.0$2.2 \mathrm{~mm}$ (Figure 6, 7,8). The EBUS TBNA needles exit from the insertion tube at $20^{\circ}$ angle. To date, a new EBUS is available: it is the EBUS Olympus BF-UC190F.

There are various commercially available EBUS TBNA needles: 21, 22 and 25 gauge has been developed for tissue sampling. New EBUS-TBNA needles 19 gauge have recently been introduced; they are more flexible and seem to allow easier access to the most difficult lymph node stations.

We have first evaluations on numerically limited cases. Real effectiveness requires more studies.

\section{EUS}

Similarly to EBUS, EUS is performed with a "dedicated" echoendoscope, allowing real-time visualization of FNA, usually used in the past by gastroenterologists and cardiologists. Different linear EUS scopes are available, presenting with an oblique viewing direction of $40^{\circ}$, a scanning range of $100^{\circ}$ to $180^{\circ}$, a frequency range of $5-12 \mathrm{MHz}$, a 3.7-3.8 $\mathrm{mm}$ diameter integrated working channel with elevator, a bending capability of up/down (130-160\%/90$\left.160^{\circ}\right)$ and left/right $\left(90^{\circ}-120^{\circ} / 90^{\circ}-120^{\circ}\right)$, all incorporating color and power Doppler.

\section{EUS-B-FNA}

In the last few years EBUS has disseminated from academic centers to community-based hospitals and is now an important equipment in most bronchoscopy unit while the EUS is not so diffused in the bronchoscopy unit. Gradually more chest physicians are also inserting the EBUS scope into the esophagus due to its advantage and encouraged by their familiarity with the equipment.

The EUS-B-FNA consists in the mediastinal lymph node evaluation and sampling by the introduction of an EBUS bronchoscope into the esophagus instead of into the airways. Differently from EUS, for EUS-B, the flexible EBUS endoscope is inserted and advanced through the esophagus with the patient lying in the supine position (and not lying on the left side as for the EUS procedure). EUS-B- FNA might increase the diagnostic utility of EBUS-TBNA by further coverage of mediastinal LN stations and access to subdiaphragmatic site lesions.

The integration of the two techniques, EBUS-TBNA and EUS-FNA (EUS-B-FNA), significantly improves sen- 
sitivity in detecting mediastinal nodal metastases, reducing the need for surgical staging procedures. International guidelines recommend at present endosonography with fine- needle aspiration as first diagnostic step for mediastinal nodal staging in non-small-cell lung cancer and combined endosonographic procedures are now the new gold standard when performed by an experienced operator.

Compared to EBUS-TBNA, EUS-FNA and EUS-B FNA have the advantage of being comparably well tolerated with lower doses of anaesthetics and sedatives, shorter procedure time, less oxygen desaturation, less coughing; further, it offers greater scanning angles $\left(150-180^{\circ}\right.$ as against $50-60^{\circ}$ ), better imaging with a higher resolution and better visualization of very small structures, with the transducer in close contact with the target, enabling desufflation to make the lumen virtual, with no interposed cartilage between needle and target; the presence of the elevator makes the needle more maneuverable, including the option of using $19 \mathrm{G}$ needles.

It is essential to willfully understand the ultrasound anatomy and landmarks of the esophageal approach considering that there are not endoluminal references for a specific puncture site with this kind of approach. With EUS or EUS-B we can visualize and sample the regions not reachable with the endobronchial approach as the station 8,9 the adrenal gland and sometimes the 5 (if considerable enlarged). The para-aortal lymph nodes (station 6) are even more difficult to assess; biopsy (from above the aortic arch) is often difficult avoiding the large mediastinal vessels, and the transaortic approach using a 25G-needle may be used only in selected cases. 52

But using the esophageal ultrasound is often easy to sample stations reachable also with EBUS as the 4L 7. In coughing patients, getting a good sample out of a small lymph 4L with EBUS can be troublesome; in this case it is useful switch to EUS-B and puncture without cough and without cartilage rings.

It is important to keep in mind that through the esophagus approach it is difficult to visualize the sheet considering that it is a virtual lumen. The operator must be sure that the sheet is out indirectly visualizing a lack of echographic signal in the point where the sheet push on the esophageal wall not allowing the contact of the us probe in that precise point.

\section{Core basic skills}

- The first prerequisite for learning ecoendoscopy is to have a strong competence on flexible bronchoscopy and on blind TBNA technique (minimum 100 flexible bronchoscopy and 5 TBNA).

- active participation in the multidisciplinary team with radiologists, pathologists, oncologists, thoracic surgeons;

- decision on systematic versus selective approach;

- sedation and oxygenation techniques, and management of related complications;

- clinical and radiographic (CT scan and PET) evaluation of the patient and her/his comorbidities; risk evaluation and management of difficulties and complications;

- radiographic/endoscopic correlations;

- competent use of ultrasound device;

- endoscopic finding of the landmarks of tracheobronchial node stations;

- ability to visualize with EBUS mediastinal lymph nodes and vessels and their anatomic relationship;

- competent use of different sizes and types of needles and other accessories (balloons) and ability to pass TBNA needle through wall of trachea/bronchus into node;

- management of the needle specimens;

- interpretation and reporting of test findings: size, shape, margins, echogenicity, presence of internal hypoechoic zones due to the presence of necrosis, elastography;

- prevention and management of procedure-related complications.

\section{Procedural steps}

Although a huge amount of literature has been produced since its introduction, most studies have been devoted to the description of the performance characteristics associated with EBUS-TBNA, whereas papers describing the technical aspects of the procedures are quite scant. Relatively recently, however, the World Association for Bronchology and Interventional Pulmonology (WABIP) and the American College of Chest Physician (ACCP) have published guidelines aimed at describing the evidence behind the many practical aspects of EBUS-TBNA. ${ }^{53,54}$

\section{Sedation}

Adequate sedation is an important part of the procedure since it provides patient's comfort and potentially increases diagnostic yield. A recent systematic review of the literature (6 studies, 3000 patients) found out that using moderate sedation in EBUS-TBNA has comparable diagnostic yield and safety profile to deep sedation..$^{55}$ However, the Authors conclude that the decision on the method of sedation for EBUS-TBNA should be individually selected based on operator experience, patient preference, as well 
as duration of the anticipated procedure. This is probably related to the fact that most studies that assessed the role of sedation in the setting of EBUS-TBNA were observational and retrospective, and they come to different conclusions. $5,55-60$

In one of the largest observational trials, for instance, Yarmus et al. analyzed a cohort of 309 patients who underwent EBUS-TBNA in two US centers, and concluded that deep sedation improves diagnostic yield and allows to sample more lymph node stations. Several other observational trials tend to contradict these findings and suggest that both diagnostic yield and complication rate are not different in patients submitted to EBUS-TBNA under moderate or deep sedation. 56

In the only randomized controlled trial currently available, 149 patients underwent EBUS-TBNA with either moderate or deep sedation in a single institution and by a single experienced operator. ${ }^{61}$ No difference was found in diagnostic yield, but fewer patients in the moderate sedation group completed the procedure $(\mathrm{P}=0.28)$ and fewer patients in the deep sedation group $(5.3 \%$ vs. $29.6 \%$, $\mathrm{P}<0.001)$ experienced anesthesia-related complications (i.e. arrhythmias, hypoxemia, hypotension, hypertension, etc.).

Based on these data, both the WABIP and the ACCP guidelines conclude that either moderate or deep sedation are acceptable approaches for EBUS-TBNA, but underline that this conclusion should be taken with caution owing to the inherent limitations (low quality, limited size, level of evidence) of the studies that analyzed this topic.

In case of moderate sedation, in an ambulatory setting for moderate conscious sedation Midazolam (Versed; Roche Pharmaceuticals, Nutley, NJ, USA) with or without Fentanyl (Fentanyl Citrate Injection; Baxter, Deerfield, IL USA) are given intravenously before the start of the procedure. A local anesthesia with lidocaine is applied on larynx some minute before the bronchoscope is inserted orally. Lidocain is also sprayed on larynx and airway through the instrument channel. Electrocardiogram, pulse oximetry, and blood pressure should be monitored during the procedure. ${ }^{62}$

In case of general anesthesia, endotracheal tube, rigid bronchoscopy or laryngeal mask can be used. Cough reflex is minimize, so the operator could better perform the procedure.

Both the endotracheal tube or the rigid bronchoscope should be higher endotracheal placed if a sample of the upper paratracheal nodes is required. ${ }^{62}$
Use of the scope

A range of instruments with linear transducers suitable are available and one of the most evident differences between those and the normal scope is the angle of vision that can vary from $10^{\circ}$ to $45^{\circ} .63$

The operator has to be trained to use the scope in a different way comparing to videobroncoscope. In fact to obtain a straight view the bronchoscope needs to be slightly flexed down, while to advance the operator should return to the neutral position in order to avoid the trauma of the tracheobronchial wall. It can be useful to alternate the straight view (with the scope flex down) to know the scope's position, and the angle view to advance within the airway. ${ }^{62}$

EBUS is usually inserted orally into the trachea, but few physicians use the nose approach when it's possible, even if there are no evidence to recommend this approach.

Once the operator has identified the larynx, he/she can advance and pass through the vocal cords visualizing the anterior angle of the glottis because of the angle of view. Do not force the scope into the glottis, because the tip is not visible and may cause dislocation of the cartilage. ${ }^{62}$ It is important to know how to manage the scope and all the instruments in order to reach a good aspirate and avoid the damage of the bronchoscope.

The EBUS scope could be inserted into the esophaghous for a EUS-B procedure. In this case the scope must be flex down when the larynx is visualised, and slightly advanced behind the posterior region of the larynx, looking for the superior esophageal sphincter. You can ask to the patient to swallow while you gently try to insert the scope; in case of resistance do not force the scope and use some water to hydrate. Similarly to EBUS, EUS is performed with a "dedicated" echoendoscope. Procedure is performed with the patient lying on his/her left side, and it begins once the patient is adequately sedated, either under mild sedation with midazolam, or under deep sedation with anesthesia care, based on the internal structure organization. The instrument is introduced through the mouth (through the use of a mouthpiece), and gently pushed until the gastric wall. From here the operator should know how recognize anatomical structures on ultrasound in order to find the regions of interest. Through the introduction of a 22 gauge needle (also available 19,21 and 15 gauge needles) in the operating channel of the echoendoscope, EUS-FNA can be performed under real-time ultrasound guidance. The risk of infection or bleeding is negligible, complications are rare, and no mortality has been reported. EUS-FNA allows easy access to the subcarinal region 7 , to the left paratracheal 
region (4L), and partially to the left hilar region (10L). It also allows evaluation of the lower mediastinum including paraesophageal region 8 , and pulmonary ligament region 9. Detection of region 5 is also possible if lymph nodes are considerably enlarged, whereas in small lymph nodes EUS-FNA might be more difficult or impossible into this region, due to interposition of the pulmonary artery/aorta. The para-aortal lymph nodes (station 6) are even more difficult to sample, due to the proximity of the large mediastinal vessels. Due to the anatomy of the esophagus, which is located behind and to the left of the trachea, EUS-FNA is not recommended for the right-sided paratracheal and hilar located LN (2R, 4R, 10R), since their visualization is prevented by the air contained in the trachea, nevertheless is possible sometimes to individuate this station and the azygos vein. Importantly, EUS-FNA is also capable of detecting metastatic disease in subdiaphragmatic sites, such as the left adrenal gland, celiac lymph nodes, and the left lobe of the liver.

\section{Visualization of lymph nodes}

Once the bronchoscope is introduced into the airway a sonographic mapping of the nodal and vascular structures of the mediastinum should be performed, and after that the target regions are selected, based on a predetermined strategy. ${ }^{7}$

To adequately perform this procedure a perfect knowledge of the mediastinal anatomy on CT scan is mandatory, considering the specific lymph node stations according to the new International Association for the Study of Lung Cancer (IASCL) lymph node map; 52 and be able to correlate it to the ultrasound landmarks (both EBUS and EUS) and the endobronchial specific puncture site. ${ }^{62}$

The endoscopic image and the corresponding ultrasound one can be visualized simultaneously on two different displays or on a two-screen display.

By flexing up the scope, the tip can have contact with the trachea/bronchial wall and the region of interest can be visualized. Try to reach every target with slow movement of the scope in each region of interest in order to have an accurate overview of every zone. ${ }^{6}$

If the ultrasound imaging is not optimal, a latex balloon should be attached to the tip of the EBUS and inflated with normal saline. Only 0.3 to $0.5 \mathrm{~mL}$ of saline is necessary to inflate the balloon during the procedure. ${ }^{6}$

In the EBUS approach a well-described endobronchial landmark is helpful to find the site of sampling of each node's station. The lymph node stations can be recognized both with EBUS and EUS-(B), through anatomic land- marks and mediastinal vessels identifiable on ultrasound image.

These landmarks are even more important for the esophageal approach considering that, in this case, no endoscopic reference sites of puncture are present. EBUS and EUS landmarks are therefore described, and the knowledge of these are fundamental for the echoendoscopic best practice. 52

The US processor has adjustable depth $(2-9 \mathrm{~cm})$, gain and frequency (range: 5 and $10 \mathrm{MHz}$;). It also has Doppler capabilities to identify blood flow in vessels, distinguishing them from lymph nodes. ${ }^{63,} 64$ Together with elastography and the echographic characteristics the Doppler also allows to better define the characteristics of each lymph node, helping in distinguish among benign and malignant nodes.

It is recommended to use $7.5 \mathrm{MHz}$ of frequency a $4 \mathrm{~cm}$ of depth as a routine. ${ }^{63}$ It could be useful to adjust these parameters on the basis of how much superficial the region of interest is. In case of superficial and small node (i.e. 7 $\mathrm{mm}$ ), it is better to use an higher frequency, a small depth and adjust the focus on the region of interest

At the contrary for big and/or deep lesions use a lower frequency and a big depth could be helpful to obtain a better characterization of the region of interest.

Moreover, is possible to measure the dimension of the lesions comparing them with the CT scan images and better evaluate the need of a sampling.

For all these reasons having a good background of ultrasound competence before to performing echoendoscopy is imperative.

\section{Needle aspiration}

The management of the dedicated needle is one of the most specific competence for EBUS so the assistant and the operator should know well the needle characteristics.

Before inserting the needle in the channel of the bronchoscope the proper setting of the needle should be verified with a double check (operator-assistant): The sheath and the needle adjuster knob should be pulled up completely and locked in order to secure the entire needle into the sheath and the sheath into the operating channel of the scope. ${ }^{62}$

The internal stylet should be completely inside the needle channel.

The EBUS-TBNA needle is fastened into the working channel of the bronchoscope with the scope in neutral position with the tip of the bronchoscope not flexed otherwise it's possible to damage the EBUS scope. During this 
procedure the operator will lose the echographic view of the region of interest that later can search again.

Once the needle is locked to the EBUS scope, the sheath is advanced out of the end of the scope until it can be visualized, then is locked. When the needle is blocked inside the scope, sometimes the operator can have some difficulties to find again the perfect echographic view region of interest. ${ }^{62}$ It happen because the tip of the scope become stiffer with the needle inside and could not have a perfect contact with the mucosa. The same thing can happen if the sheath is pushed out too far. In these cases the operator should try to pull in the sheath in order to have out of the working channel the minimum of it (visualizing only the tip of the sheath).

The sheath should be always visible before the needle is pushed out as well when the needle is inside the lesion. ${ }^{62}$

In order to visualize the node on the ultrasound image, the tip of the bronchoscope should be flexed up for contact with the trachea/bronchial wall. The sheath should be wedged in between the cartilaginous ring, if possible.

After the needle adjuster is unlocked, you can choose to relock it at precise distance (so the needle can be pushed out maximum until this distance, e.g. $3 \mathrm{~cm}$ ) or left it free allowing the maximum exit of the needle $(5 \mathrm{~cm})$.

When the operator pushes the needle out the assistant should secure the bronchoscope by the patient's mouth and you should immediately view the needle inside the node. In order to facilitate the penetration it is suggested to slightly retract the internal stylet. Anyway, during this procedure, the operator can lose the ultrasound image because the airway may be pushed away from the probe when the needle penetrate through the trachea/bronchial wall.62 To avoid this, it could be useful to push the needle out with a rapid and controlled movement (always with the scope secured at the patient's mouth), moreover the assistant can give a little push at the same time the operator pushes the needle out.

In case a cartilage ring is encountered during TBNA, the bronchoscope is moved a little bit up or down so that the needle will go through the intercartilage space. The operator must keep the endoscopic images clear during the procedure with a perfect view of the needle inside the node in order to avoid puncturing undesirable region. ${ }^{62} \mathrm{Af}$ ter penetration you should clearly view the needle inside the node otherwise you can try to find the exact scan with slow and small rotation of the scope. When the needle is inside the node, the assistant can use the internal stylet to clear out the internal lumen, which may become clogged with bronchial cells.

The tissue sampling may be performed either with or without suction. There is no evidence to recommend one specific procedure. For big lymph node or if the ultrasonographic image of the node shows an high vascularization of it (using color-doppler) the operator can take the sample without suction. If the material achieved is not enough it is suggested to apply suction for the following punctures.

On the contrary when the node to sample is little it could be useful to start with suction because the movement of the needle inside the node will be limited. If significant blood contamination is seen within the aspirated material or at ROSE, it's suggested to not use suction for the following punctures in order to obtain a better quality sample.

If suction is applied, the internal stylet is removed and the syringe is applied on top of the needle. The negative pressure is applied when the needle is inside the lymph node. EBUS-TBNA may be performed without suction; slow pulling the internal stylet in order to create a little negative pressure inside the needle. ${ }^{62}$

The needle is moved back and forth within the lymph node (10-20 times). Pull the needle back into the outer sheath until you hear the click on the needle. Lock the needle and pull the outer sheath back into the channel of the bronchoscope. Retrieve the needle for collection of the specimen. 62

In the absence of rapid on-site evaluation (ROSE) in patients suspected of having lung cancer and undergoing EBUS-TBNA for diagnosis, it is important to perform a minimum of 3 separate needle passes per sampling site; 4 needle passes should be obtained from the target whenever molecular testing is planned. ${ }^{54}$

EBUS-TBNA can be performed with a wide array of needles of different size (25-gauge, 22-gauge, 21-gauge, and 19-gauge) and materials (nitinol, stainless steel).

Based on these evidences, both the international guidelines suggest that there is currently insufficient evidence to recommend a specific needle size or type.

Evidence regarding the key technical aspects of EBUSTBNA

\section{Number of needle passes}

A limited number of studies assessed the number of needle passes (number of aspirates per lymph node) needed to optimize the diagnostic yield of EBUS-TBNA in patients with intrathoracic lymphadenopathy, as well as the number of needle passes aimed at achieving a complete genotyping in patients with known/suspected advanced lung cancer. ${ }^{3,65-67}$

Lee et al. evaluated the number of needle aspirates needed to optimize specimen's adequacy and diagnos- 
tic yield in 102 potentially operable patients undergoing EBUS-TBNA for mediastinal staging of known/suspected lung cancer. ${ }^{3}$ The Authors found out that $100 \%$ adequacy and $95 \%$ sensitivity were achieved by the $3^{\text {rd }}$ needle aspiration and did not increase with a $4^{\text {th }}$ one. ${ }^{3}$

Two studies assessed the same topic in sarcoidosis. ${ }^{65}$ In the study by Oki et al. 109 patients underwent EBUSTBNA for 184 lesions. ${ }^{65}$ The cumulative yields through the first, second, third, fourth, fifth, and sixth passes for the main target lesion were $63 \%, 75 \%, 82 \%, 85 \%, 86 \%$ and $88 \%$, respectively. In the 55 patients that underwent EBUS-TBNA for multiple lesions, the cumulative yields of 2 passes per lesion for 2 lesions (total of 4 passes) and of 4 passes for single lesions were 86 and $84 \%$, respectively $(\mathrm{P}=1.00)$. The Authors conclude that at least 4 needle passes should be carried out from a single or from multiple lymph nodes to optimize the diagnostic yield of EBUS-TBNA in patients with suspected sarcoidosis. Sun et al. performed a prospective study of EBUS-TBNA in sarcoidosis aimed at determining the predictive factors of diagnostic success. ${ }^{66}$ In the multivariate analysis, the short axis diameter and more than 1 needle pass per lymph node were independent risk factors associated with a positive pathology. The authors conclude that the operators should select the largest mediastinal or hilar lymph node accessible and puncture with 3 to 5 passes to optimize the diagnostic yield of EBUS-TBNA in sarcoidosis if ROSE is unavailable. ${ }^{66}$

A single retrospective study analysis has examined the number of EBUS-TBNA aspirations (using a 21-gauge needle and ROSE) required to ensure maximal diagnostic yield for mutational analysis (EGFR, KRAS and ALK). ${ }^{67}$ This retrospective study showed that specimens were adequate for molecular analysis in $95 \%$ of all cases with a median number of 4 aspirations per patient. ${ }^{67}$ Based on this study, the WABIP guidelines suggest that a total of 4 needle passes should be obtained from the target whenever molecular testing is planned, wherever the ACCP guideline recommend that additional samples, beyond those needed to establish the diagnosis, be obtained for molecular analysis.

Use of suction

EBUS-TBNA can be carried out with or without suction. The difference between the two methods is that in the technique without suction, also referred to as transbronchial needle capillary sampling (TBNCS), the needle is moved back and forth within the target lymph node without applying continuous suction through a $10-20 \mathrm{~mL}$ syringe.
Only one randomized controlled trial addressed this topic. Casal et al. randomized 115 patients towards EBUSTBNA with or without suction, and found no differences in terms of adequacy ( $88 \%$ vs $88 \%$ ), overall diagnostic yield (36\% vs. 34\%), diagnostic yield for malignancy (28\% vs. $26 \%$ ), and sample quality. ${ }^{68}$ Interestingly, concordance rate between the two techniques was high, ranging from $83.3 \%$ to $95.8 \%$ for adequacy, diagnostic yield and specimen quality. 68

A few more studies have assessed the impact on different levels of pressure suction during EBUS-TBNA. ${ }^{69,70}$ Boonsarngsuk compared EBUS-TBNA with no suction, -20 and $-40 \mathrm{~cm} \mathrm{H}_{2} 0.69$ The diagnostic yield of EBUSTBNA with -20 and $-40 \mathrm{~cm} \mathrm{H}_{2} 0$ was similar (75.8 and $83.3 \%$, respectively). The yield of EBUS-TBNA carried out without suction was lower $(63.6 \%)$, but this result may be influenced by the abnormally high rate of inadequate samples $(29 \%)$ retrieved in the no-suction group. ${ }^{69}$ Shiroyama et al. compared EBUS-TBNA with suction set at -20 (low-pressure group) and $-30 \mathrm{~cm} \mathrm{H}_{2} \mathrm{O}$ (highpressure group) and found out that sensitivity, specificity and accuracy were not statistically different between the two groups. However, a significantly higher number of patients in the high-pressure group had diagnostic histology cores as compared to the low-pressure group (90 vs. 28).

Based on the results of these studies both the WABIP and the ACCP Guidelines conclude that EBUS-TBNA can be performed either with or without suction. However, many aspects related to the role of suction with EBUSTBNA, such as the possible differences in the yield for cancer genotyping and the possible differences in the yield with different needle size remain unknown and require further study.

\section{Needle size}

EBUS-TBNA can be performed with a wide array of needles of different size (25-gauge, 22-gauge, 21-gauge, and 19-gauge) and materials (nitinol, stainless steel). Although some studies have compared the diagnostic success of EBUS-TBNA performed with needles of different size, ${ }^{71-73}$ only two randomized trials analyzed this topic. 74,75

Oki et al. randomized 60 patients to undergo EBUSTBNA with either a 21-gauge or a 22 -gauge needle. ${ }^{74}$ No differences were found between the two groups in terms of diagnostic yield, specimen adequacy, and retrieval of histology cores. ${ }^{74}$ Very recently, Dooms et al. performed a randomized controlled trial aimed at comparing the recently introduced Flex 19-gauge needle 
with a standard 22-gauge needle in 78 patients with suspected lung cancer. ${ }^{75}$ The primary endpoint was the procurement of a histology core. The secondary endpoints were diagnostic yield, specimen quality (especially its bloodiness), tissue surface area, procedure-related complications, and performance for next generation sequencing (NGS). ${ }^{75}$ Surprisingly, the only advantage associated with the use of the Flex 19-gauge needle was a trend towards a larger tissue surface area of histology cores, whereas no difference was found for any of the remaining endpoints, including clinically relevant ones such as diagnostic yield, complication rate, and success of NGS testin. 75

Based on these evidences, both the international guidelines suggest that there is currently insufficient evidence to recommend a specific needle size or type.

\section{Stylet use}

Dedicated EBUS-TBNA needles come with an inner stylet which is commonly used to expel the tissue (usually airway wall material) that is loaded into the tip once it it thrust through the airway wall into the target lesion (i.e. lymphadenopathy). Recently Scholten et al. performed a study aimed at verifying if the inner stylet of EBUS needle is really useful. ${ }^{76}$ The Authors enrolled 121 patients and sampled 194 lymph nodes, using for each sampled lymph node both the with stylet and without stylet technique. ${ }^{76}$ Interestingly no differences were found between the stylet and no-stylet groups in terms of sample adequacy $(82 \%$ vs. $87 \%$, respectively), diagnostic yield $(25.7 \%$ vs. $25.2 \%$ in the per lymph node analysis). There was a high degree of concordance for both adequacy (84\%) and diagnostic yield $(95.4 \%)$ between the two techniques. The authors conclude that omitting the stylet use during EBUS-TBNA does not affect the diagnostic outcomes and reduces the complexity of the procedure (Table II). ${ }^{77}$

Specimens

Once you get a good specimen it is extremely important to process the specimen in a proper way to achieve maximum results. Handling of the specimen may differ between centers and the operator should use the type of preparation according with his pathologist's preferences. ${ }^{62}$

For pushing out the specimen the internal stylet can be used and if the material is not enough, can be blowed air with a syringe through the needle. The first few drops are placed on the slide glass and then smeared in order to obtain 2/4 slide; one slide are air-dried and immediately stained for ROSE and the other/s is/are fixed in alcohol 95\% for Papanicolaou. The slides should be fixed quickly in order to avoid phenomena of desiccation e/o cellular degeneration and should be constituted only by one cellular layer, in thicker preparations the interpretation is difficult.

The remaining specimen can be placed in a solution that allows the preparation of cell block, core tissue preparations, blank slides for ancillary test. The needle is washed with saline into cytolit fixative to remove remaining cells for thin prep or cell block preparation. ${ }^{78}$

All this preparation facilitates IHC examination for proper subclassification and the molecular analysis. Sometimes, especially when the diagnosis has already been confirmed by ROSE, the operator can directly use the specimen for one of this preparation, without preparing any slides.

To prepare a cellblock the material inside the needle should be placed in formalin or cytolit preparation blowing air with a syringe through the needle. Cell blocks were stained with hematoxylin-eosin and when indicated with immunohistochemical stains. 80

To prepare $\mathrm{CBs}$ using the TCC-CB (tissue coagulum clot-cell block) method, the material within the needle was pushed out using the inside stylet, instead of using a syringe. The material was collected onto a piece of filter paper with the needle tip directed in a tight circular motion to build up a cone shaped clot of tissue and blood mixture. The clot was slightly air dried on the filter paper, mostly to ensure that the coagulum was congealed and the cellular elements were not quickly dispersed in a liquid medium. The tissue coagulum was wrapped with filter paper, gently slid into a formalin container, and processed in the histology laboratory. After histological processing, 4-5 micron sections were mounted on uncharged glass slides. Sections stained with hematoxylin and eosin (H\&E) were used to assess cellularity and morphology.79

Especially when the material on the glass slide are abundant and bloody, it can be left there coagulating for some minutes, and once coagulated transferred to $10 \%$ formalin through the use of a blunt needle or a bisturi. This clot is partly stained $\mathrm{H} \& \mathrm{E}$, and partly used for molecular and immunohistochimic analysis. Any BCC that was expelled on the slide was then transferred to $10 \%$ formalin using to blunt needle.

When a core of tissue is identified on the slide, it's important avoid to leave it there because it would be wasted material if stained as a slide. Therefore, it is important to take it with a blunt needle and transferred in $10 \%$ formalin where can be processed adequately. 
TABLE II.-Summary of the main recommendations from available guidelines.

- Insertion of endoscope through upper airways and vocal cords, bearing in mind the correct angles providing different endoscopic visualizations

- Presentation of main lymph nodes $(2,4,7,10,11)$ and vascular stations and their relationship

- positioning of the transducer

- biopsy sampling, according to the 18 procedural steps described by Mehta:77

1. Advance EBUS needle through the working channel with scope in neutral position

2. Secure needle assembly by sliding the flange, locking it in place

3. Release the sheath screw

4. Advance and lock the sheath when it is visualized at the top righthand corner of the monitor

5. Locate the target lymph node to be sampled using US imaging

6. Release the needle guard

7. Advance the needle using the quick "jab" method

8. Visualize needle entering target node with US

9. Move the stylet in and out a few times to dislodge debris within the needle

10. Withdraw the stylet

11. Attach suction syringe to the needle

12. Apply suction

13. Move the needle back and forth within the node $>10$ times

14. Release suction

15. Retract the needle into the sheath

16. Secure the needle guard

17. Unlock the needle assembly

18. Remove the needle and sheath; collect the specimen

- correct placing of specimen on slide and cell block

- Preparation and interpretation of ROSE

Acquire a competence about the acquisition and Preparation of Specimens from EBUS-TBNA is fundamental as it is the knowledge of the WABIP guideline on this argument.

ROSE

One of smears obtained by EBUS TBNA can be air-dried and immediately stained. Diff-Quik is the mostly used procedure but other stains like rapid hematoxylin, can be used, based on the pathologist's preferences. Rapid on-site evaluation of the aspirates does not increase diagnostic yield or specimen's adequacy, but is associated with a fewer number of needle passes and with a lower requirement of additional bronchoscopy procedures to make a final diagnosis. ${ }^{81}$

Reduce the number of lymph node's stations to sample can have a high impact on the everyday practice; for example, if ROSE shows malignant cells in a N3 lymph node, additional aspirations of the $\mathrm{N} 2$ or $\mathrm{N} 1$ is not necessary.

So the role of the cytopathologist is to:

- define if a sample is adequate;

- decide if the material is enough for a precise diagnosis;

- formulate a preliminary diagnosis;
- decide if the material is sufficient for the eventual ICC and molecular analysis;

- decide which kind of sample preparation are indicated in the different moment of the exam.

It is demonstrated that also a trained pulmonologist can reach a good competence on this kind of evaluation. For this reason also the pulmonologist should learn ROSE or at least to know how to interpret the cytologic evaluation in order to maximize the efficiency of the procedure.

\section{Evidence regarding $R O S E$}

Only three randomized trials evaluated the influence of rapid on-site evaluation on the success diagnostic rate of EBUS-TBNA. ${ }^{82-84}$ Oki et al. randomized 120 patients with mediastinal lymphadenopathy to undergo EBUS-TBNA with or without ROSE by a cytotechnologist. ${ }^{82}$ Although patients in the ROSE group had less biopsy sites sampled $(11 \% v s .57 \%, \mathrm{P}<0.001)$ and a lower number of punctures per lymph node (2.2 vs. 3.1, $\mathrm{P}<0.001)$, mean bronchoscopy time ( $22.3 v s .22 .1 \mathrm{~min})$, sensitivity $(88 \%$ vs. $86 \%)$ and diagnostic accuracy ( $89 \%$ vs. $89 \%$ ) were similar between the two groups. ${ }^{82}$ In a study aimed at evaluating the role of EBUS-TBNA with and without ROSE for lung cancer genotyping, Trisolini et. al. enrolled 197 patients with suspected lung cancer. ${ }^{83}$ Again, neither adequacy $(94.9 \% \mathrm{vs}$. $97.7 \%)$ nor sensitivity $(96.9 \%$ vs. $95.1 \%)$ were different in the ROSE as compared to the no-ROSE groups, whereas a $10.5 \%$ more patients in the ROSE group achieved a complete cancer genotyping. ${ }^{83}$ Finally, Madan et al. performed a complex randomized trial aimed at evaluating the role of conventional versus EBUS-guided TBNA with and without ROSE in sarcoidosis. ${ }^{84}$ Eighty patients were randomized 1:1:1:1 to undergo c-TBNA without ROSE, c-TBNA with ROSE, EBUS-TBNA without ROSE, and EBUS-TBNA with ROSE. In the two EBUS groups, no difference in diagnostic yield was seen in the ROSE group $(67 \%)$ versus the no-ROSE group (68\%). ${ }^{84}$

More recently, a systematic review with meta-analysis (5 studies, 618 patients) summarized the evidence on the impact of ROSE on the diagnostic yield of both c-TBNA and EBUS-TBNA, and confirmed that the on-site review does not increase diagnostic yield or specimen's adequacy, but is associated with a fewer number of needle passes and with a lower requirement of additional bronchoscopy procedures to make a final diagnosis. 81

Based on these findings, both the WABIP and the ACCP guidelines suggest that there is insufficient evidence to recommend that ROSE be used with every EBUS-TBNA procedure. 


\section{Procedural steps with EUS/EUS-B}

EUS and EUS-B can be safely done as an outpatient procedure in a bronchoscopy unit.

The suite should be properly equipped for patient monitoring.

A secure intravenous access is mandatory and specific anesthetic drugs should be at hand.

A certified bronchoscopist with formal endosonography training, two nurses and an anesthesiologist, in case of deep sedation or general anesthesia, should be the minimal personnel requirements to perform the procedure securely.

The step-by-step EUS-B procedure:

1) insert the scope through the mouth (through the use of a mouthpiece) into the esophagus;

2) suction should be used only in intermittent manner to avoid deflating esophageal tract completely;

3) advanced the scope under visual control to the gastric fundus;

4) from this moment on continuosus suction is mandatory to facilitate the contact between the US trasducer and the esophageal wall;

5) at the cardia region the trasducer is turned back until the abdominal aorta is clearly visualized;

6) identify the left adrenal gland (LAG) going down the aorta up to the celiac trunk and turned the scope counterclockwise (if physician standing behind a patient the trasducer turns to the left). The LAG is behind the celiac trunk;

7) the trasducer is brought back to its standard neutral position at the cardia and see in front the liver and to the right you can follow the hepatic veins to the inferior vena cava;

8) search for LFN7 station. Move the scope back from distal to the middle part of esophagus and visualized anteriorly the left ventricle, the atrioventricular valves and the left atrium. Withdrawing the scope slightly more, subcarinal lymph node (7) are clearly visible;

9) search for LFN4R station. Move slightly to the right the scope and localize the right pulmonary artery in a trasverse section. Retreating the scope and looking anteriorly behind the azygos vein the 4R staion can be found;

10) search for LFN4L station. Now rotating the EBUS scope to the left will permit to detect the lower paratracheal (4L) and deeper aort-pulmonary window LF (station 5 ) betwenn the pulmonary artery and aorta (mickey mouse effect);

11) search for $2 \mathrm{~L}$ station. As the EUS-B scope is further withdrawn, the left subclavian artery and the $2 \mathrm{~L}$ staion are identified on the left.

\section{Strategies' skills}

Competence is not only referred to the practical part, in fact the strategies in planning every single case are not less important. These are principally based on the knowledge of the recommendations from the currently published guidelines regarding diagnosis and staging of lung cancer, the EBUS technique and treatment of the specimens. ${ }^{53,54}$

To make an accurate staging with EBUS/EUS, follow a precise order of sampling is necessary and depends mainly on the side and localization of the tumor determined by CT scan findings. If possible, distant metastases (M1) should be excluded first, followed by lymph node staging in the order N3 (contralateral lymph nodes) $\rightarrow$ N2 (ipsilateral mediastinal and subcarinal lymph nodes) $\rightarrow$ N1 (ipsilateral hilar lymph nodes). For patients with suspected N2 disease infiltration of only single N2 lymph nodes (N2a, stage IIIA3) has to be differentiated from infiltration of more than one N2 lymph node region, clusters of involved lymph nodes in one or more N2 stations, or large N2 lymph nodes with extracapsular invasion (N2b, Stage IIIA4) . It is important because it can differentiate between resectable and unresctable N2.52

Based on the ERS/ESTS/ESGE recommendation it is possible to distinguish between two main kind of staging:

1. the target staging (or "Hit and run") where the operator should puncture only the nodes suspicious on CT and/ or PET. The hit and run approach can be performed in patients that does not need a staging, for example the clear advanced stage NSCLC. Moreover, especially in this last case the operator must guarantee a sufficient material for ICC and molecular analysis in order to ensure a personalized therapy. So, it is important find the more efficient examination to get appropriate material for these kind of investigations, preferring specimens (if possible; i.e. endobronchial or transbronchial biopsy) and/or clot core and cell block.

2 . A systematic echoendobronchial evaluation of the mediastinal lymph node stations can be performed with some different strategies which have in common an essential factor: the evaluation of the main mediastinal node stations, meaning at least 4R 4L 7 10R 10L 11R 11L. Sampling of at least three different mediastinal nodal stations (4R, 4L, 7). The largest node measuring $>5 \mathrm{~mm}$ (short axis diameter) on ultrasonography, as well as FDG-avid nodes within each of these nodal stations should be sampled for pathological analysis. On indication, the hylar station can be biopsied.11 The operator, based on knowledge of the guidelines, should perform a complete mediastinal staging in proven or suspected NSCLC and an abnormal mediastinum by CT 
or CT-PET. This "complete" mediastinal staging is based on the concept that identification of one malignant lymph node does not mean that mediastinal staging was optimal. One strategy regards basically the order of visualization. So it is possible to decide the order of evaluation considering where the tumor $(\mathrm{T})$ is located during a NSCLC staging. For example if " $\mathrm{T}$ " is located in the RLL is possible to evaluate 10L, 11L and 4L (representing the N3), then 7 and $4 \mathrm{R}$ (representing the N2) and at the end 10R and 11R (representing N1), follow this order also for sampling. Another strategy consists in always use the same order of evaluation. For example is often used an order linked to the six EBUS landmarks, starting from 4L, moving to 7 and then $10 \mathrm{~L} / 11 \mathrm{~L}$, azygos vein, $4 \mathrm{R}$ and at the end 10R/11R. Can be useful using this last approach because you can routinely follow the same order and automatically better remember it, but it is fundamental not to follow this order for sampling, considering that in this last case the order must always be N3->N2->N1, unless the needle is changed when the operator moves from N1 to N2 or from N2 to N3.

\section{Lymph node characteristics}

The operator should be able to analyze the lymph nodes features in order to select which nodes should be punctured considering the probability of malignancy. Sonographic characteristic are helpful in predicting lymph node malignancy both for superficial lymph nodes and for mediastinal and hilar nodes. ${ }^{85}$

The main lymph node sonographic features that can be assessed through EBUS are: 1) size (short axis) less or more than $1 \mathrm{~cm}$; 2) shape (oval or round); 3) margin (indistinct or distinct); 4) echogenicity (homogeneous or heterogeneous); 5) presence or absence of central hilar structure; and 6) presence or absence of coagulation necrosis sign 85 (Figure 9, 10).

High negative predictive values were found considering these characteristics, so that when node EBUS malignant features are not detected the true negativity of the sampled lymph node is more likely. Round shape, distinct margin, heterogeneous echogenicity, and presence of coagulation necrosis sign are instead independent predictive factors for nodal metastasis. ${ }^{86}$

Moreover a vascular image pattern classification of lymph node using Doppler-mode ultrasound during EBUS-TBNA was described. Considering the lymph node vascularization as blood-flow signals, other than central intranodal blood flow and bronchial artery inflow signal from the bronchial lumen, the operator may predict the probability of malignancy of the lymph nodes in patients

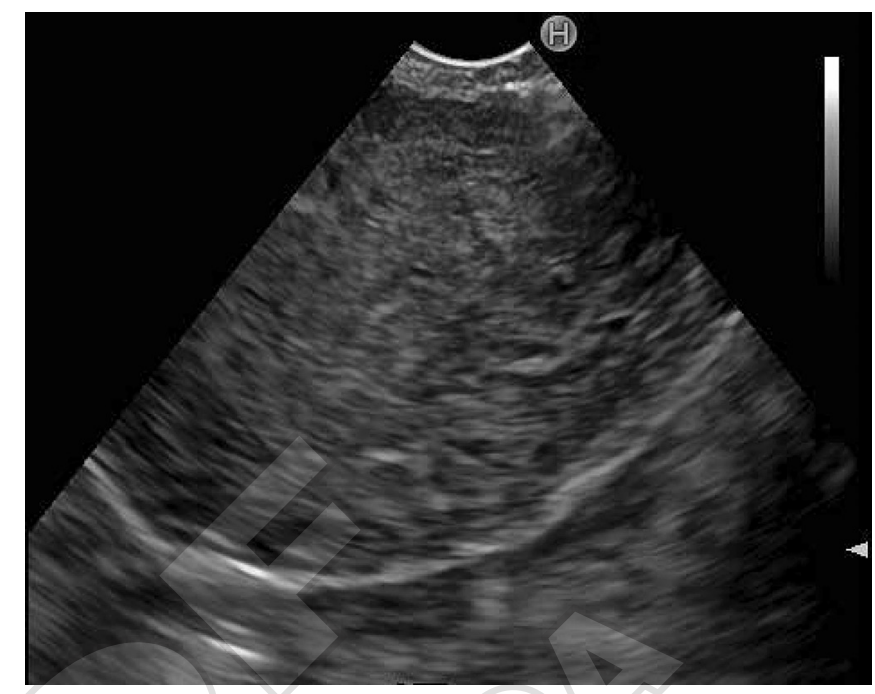

Figure 9.-Lymph node with malignant characteristics.

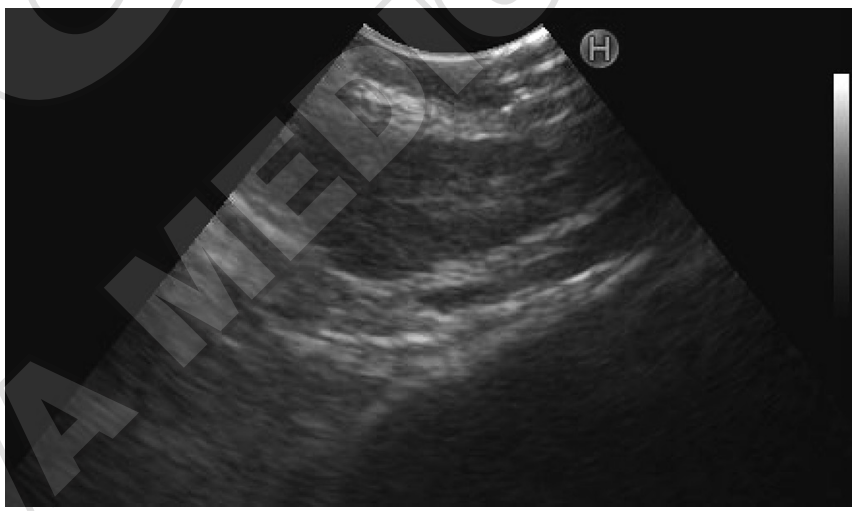

Figure 10.- Lymph node with benignant characteristics.

with lung cancer. When such features are observed the risk of metastatic node is higher and multiple needle aspiration should be performed even if the ROSE reported only benign lymphocytes. 86

Another important contribution in identifying lymph node's characteristics for a better selection of punctures site could be made by ultrasound elastography. Elastography is an imaging methodic that can assess the stiffness of different tissue considering their deformation under compression. ${ }^{87}$ The stiffness' degree is reported into a color-coded image on ultrasound display: harder tissues are shown in blue; intermediate/normal tissues in green; softer tissues in red. 88

Malignant tissues are usually stiffer than normal healthy tissues and may be distinguished through a qualitative evaluation of the color pattern or through a semiquantita- 
tive measurement (i.e. Strain ratio, Strain Hystogram (Figure 11,12$) .87,89,90$

EBUS elastography could be considered an effective diagnostic technique for the differentiation between benign and malignant lymph nodes considering the preliminary data on this method; moreover, circumscribed metastatic infiltration area could be more easily detected allowing a precise puncture of suspicious area within the node. ${ }^{91}$

A correct evaluation of these characteristics is essential for an efficient assessment of the mediastinal nodes.

The operator should be able to analyze all the lymph nodes features in order to select which nodes should be sampled based on its features. All these lymph node se-

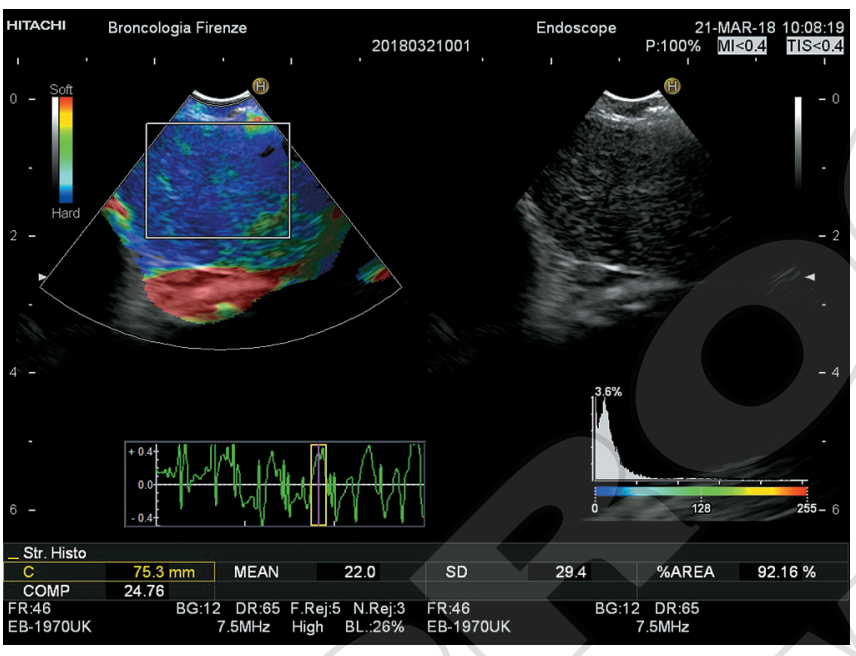

Figure 11.-Elastography-strain hystogram.

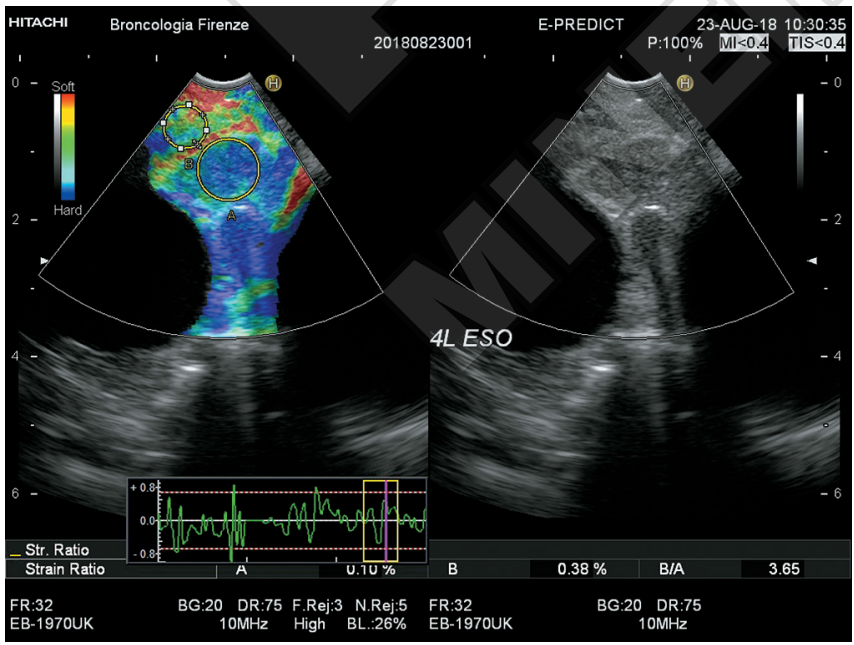

Figure 12.-Elastography-strain ratio. lection criteria could be useful especially during a EBUS/ EUS-(B) systematic staging where many lymph nodes can be detected. When all characteristics are sonographically determined not metastatic, we might be able to avoid unnecessary biopsies in such lymph nodes.

Moreover, when a node is sampled and ROSE report only benign lymphocytes, we might decide to continue the sampling on such node based on the lymph node characteristic: if the node's feature suggest benignancy we could avoid unnecessary passes and change node, if the node's features suggest malignancy subsequent needle aspirations should be taken.

This kind of approach could allow to save time in mediastinal nodal staging, could reduce the risk of false-negative cytopathological results, and could prevent to repeat endosonographic sampling procedures and surgical staging.

Practical anatomy-echoendoscopy correlation

Lymph node stations reachable with EBUS and/or EUS(B) are reported with the specific images and anatomic features of each one

Station 1: low cervical, supraclavicular and sternal notch nodes 92,93

Anatomy

- Upper border: lower margin of cricoid cartilage.

- Lower border: clavicles bilaterally and, in the midline, the upper border of the manubrium.

- The midline of the trachea serves as the border between $1 \mathrm{R}$ and $1 \mathrm{~L}$.

\section{Echoendoscopy}

When enlarged and adiacent to the trachea is possible to find these nodes in the first centimetres of the trachea, just below the vocal cords. From 9 o'clock position to 12: 1L; from 12 o'clock position to $151 \mathrm{R}$.

There is not a specific US pattern.

Note: it is a rare detection but always represent a N3 in the NSCLC staging (Figure 13).92, 93

Station 2 (upper paratracheal lymph nodes) ${ }^{92,93}$

$$
\text { - } 2 \mathrm{R}
$$

\section{Anatomy}

- Upper border: manubrium and apex of lungs (laterally). 
- Lower border intersection of caudal margin of left brachiocephalic vein with the trachea.

- Located to the right of the left lateral border (not the midline) of the trachea.

\section{Echoendoscopy}

One third of the distance of the trachea from the vocal cord represent the endobronchial position in which we can normally find this node. In this area, around 1-2 o'clock position is possible to individuate the right common carotid artery and the right subclavian artery that are normally near this lymph node station.

Both the upper border and the lower border of this station is difficult to define with endobronchial ultrasound. A trick can be used to individuate at least the lower border of this station, finding the lower border of $2 \mathrm{~L}$ (superior rim of the aortic arch) and then turning the scope on the right remaining at the same cranio-caudal level (Figure 14).

- $2 \mathrm{~L}$

\section{Anatomy}

- Upper border: manubrium and apex of lungs (laterally).

- Lower border: superior border of aortic arch.

- Located to the left of the left lateral border (not the midline) of the trachea.

\section{Echoendoscopy}

As for the $2 \mathrm{R}$ the one third of the distance of the trachea from the vocal cord represent the endobronchial position but it's important to remember that the $2 \mathrm{~L}$ are located to the left of the lateral border of the trachea, so that can be found at 9-10 o'clock position.

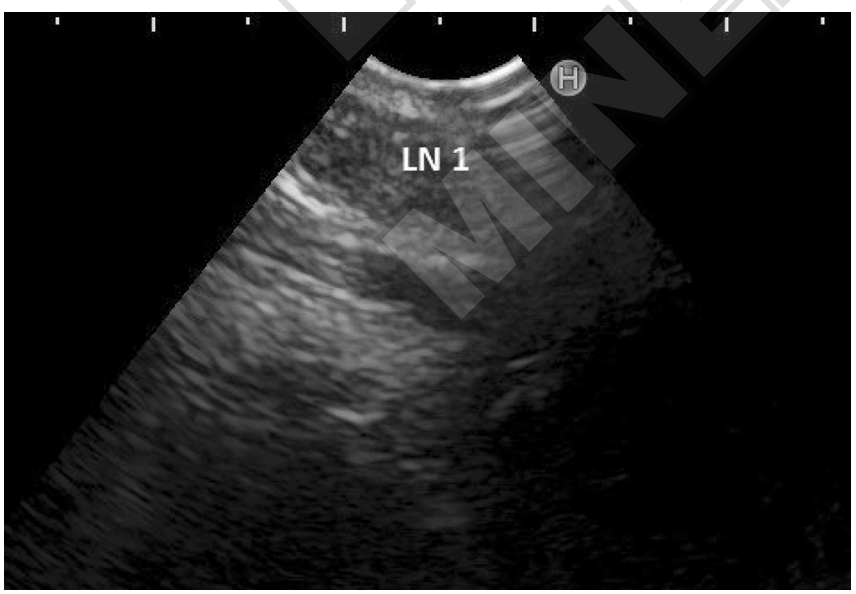

Figure 13.-Lymph node station 1.
The left jugular vein and the left common carotid can be individuated in this area helping as a landmark, moreover the lower border of this station is clearly visible at EBUS (superior rim of the aortic arch).

This station can be reached also through an esophageal approach, finding also in this case the superior border of the aortic arch and exploring the region upon this landmark.

Station 3A (prevascular lymph nodes) ${ }^{92,}, 93$

Anatomy

- Upper border: apex of the chest

- Lower border: carina,

- Anterior border: sternum.

- Posterior border: the superior vena cava (SVC) on the right and the left common carotid artery on the left.

\section{Echoendoscopy}

Sometimes these nodes can be individuated, but being located anterior to the great vessels (common carotid and jugular vein), they cannot be sampled. It is a rare detection. ${ }^{92,93}$

Station 3P (retrotracheal lymph nodes) ${ }^{92,93}$

- Upper border: apex of the chest.

- Lower border: carina.

- Anterior border: the posterior wall of trachea.

\section{Echoendoscopy}

This station can be reached exploring the posterior wall of the trachea (6-7 o'clock position). It is a rare detection but can be usually reached also with EUS-(B). There are not specific structures to be used as landmarks. ${ }^{92,93}$

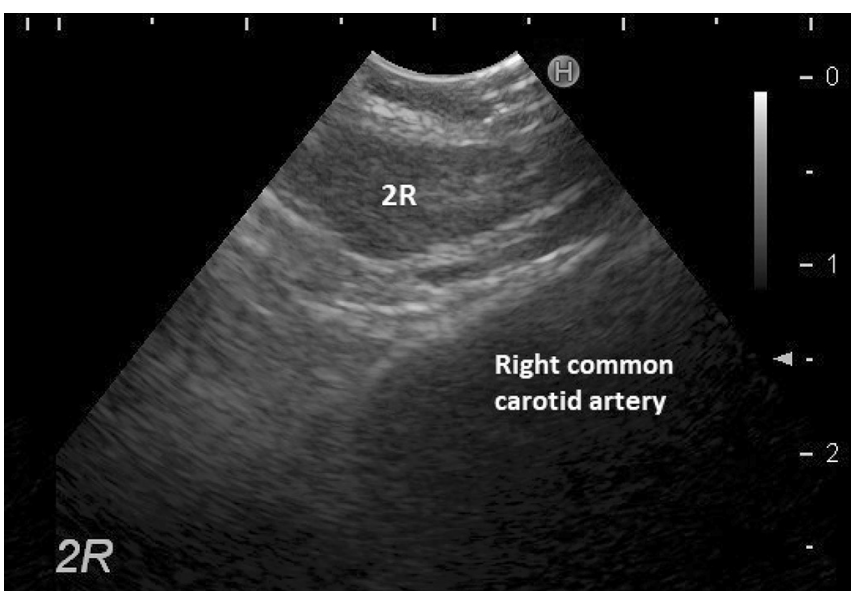

Figure 14.-Lymph node station 2R. 
Station 4 (Lower Paratracheal Lymph Nodes) ${ }^{92,93}$

- $4 \mathrm{R}$

Anatomy

- Upper border: intersection of caudal margin of left brachiocephalic vein with the trachea

- Lower border: lower border of azygos vein;

- Located to the right of the left lateral border (not the midline) of the trachea.

\section{Echoendoscopy}

This station is often located at 1-2 o'clock position, twofour intercartilage space above the carina. At this level the node can be positioned just in front of the superior vena cava distally visible as a specific landmark (img). It is useful to find the azygos vein (representing the lower border of this station) and then explore the region above this vessel in order to easily find this region.

The nodes of this station can extend anterior to the trachea. At this level are known as anterior carinal lymph nodes and are located at 11.30-12 o'clock position. It is fundamental to adequately explorate all the 4R region, without forgetting this anterior zone.

A trick can be used to individuate the upper border of this station, finding the upper border of $4 \mathrm{~L}$ (superior rim of the aortic arch) and then turning the scope on the right remaining at the same cranio-caudal level.

Even more important is individuate the lower border of this station, represented from the lower border of the azygos vein. When you are looking for the azygos (2 o'clock position at the end of the trachea) you can make sure that the individuated vessel is the azygos finding the point in

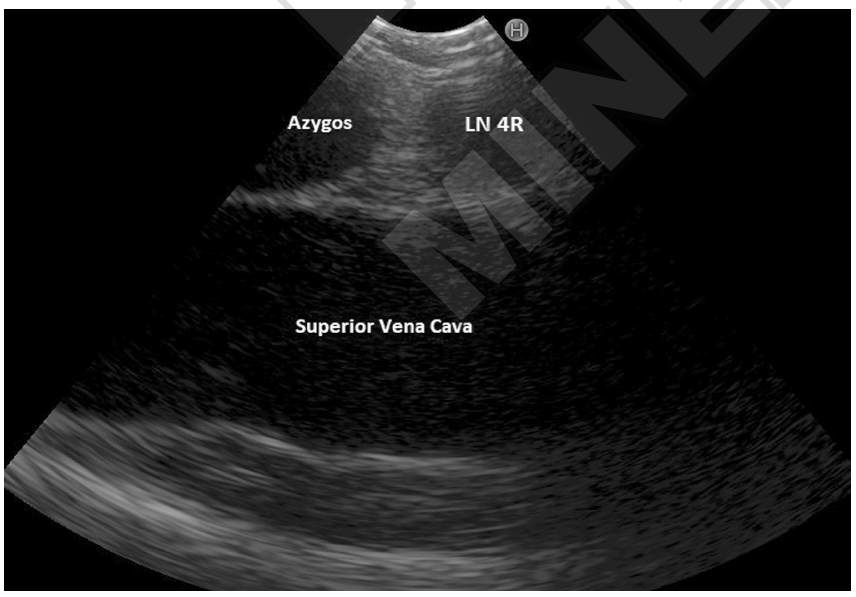

Figure 15.-Lymph node station 4R. which the azygos converges into the superior vena cava with a slightly rotation of the scope. The azygos vein distinguishes between $4 \mathrm{R}$ and 10R station and this is essential in the NSCLC staging (Figure 15).

$$
\text { - } 4 \mathrm{~L}
$$

\section{Anatomy}

- Upper border: superior border of aortic arch.

- Lower border: superior rim of the left main pulmonary artery.

- Located to the left of the left lateral border (not the midline) of the trachea.

- The left lateral-most extent of $4 \mathrm{~L}$ is the ligament arteriosum, separating this station from station 5 .

\section{Echoendoscopy}

This station is located at the 9 o'clock position, at the level of the carina, just above the left main bronchus ostium. At this level is possible to individuate one of the more common landmarks: the so called micky mouse window. Infact it is possible to see the aorta and pulmonary artery and the 4L lymph node (representing the head of micky mouse) between this main vessel (representing the two ears of micky mouse) medial to the ligamentum arteriosum.

Moreover is also easy to recognize the upper and lower borders of this station, considering that are pretty much included in the "micky mouse" window.

This station is easy to visualize through the esophageal approach. In fact also in this case it is possible to recognize the "mickey mouse effect" just withdrawing the scope slightly from the heart view and rotating the scope to the left (Figure 16).

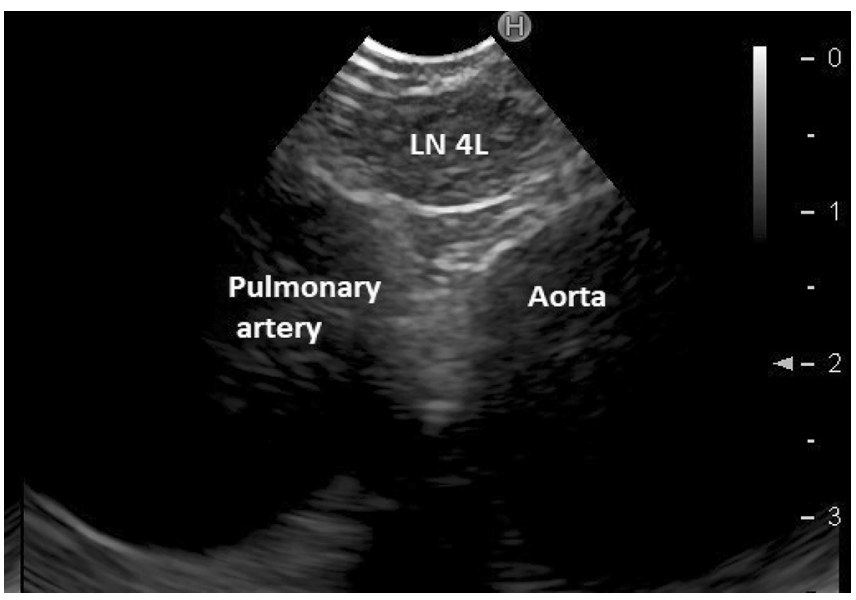

Figure 16.- - Lymph node station 4L. 
Station 5 (Subaortic Lymph Nodes) ${ }^{92,}, 93$

Anatomy

- Upper border: lower border of aortic arch.

- Lower border upper rim of left main pulmonary artery.

- Station 5 lymph nodes are located lateral to the ligament arteriosum, that separate this station from 4L).

\section{Echoendoscopy}

This lymph node station is visible at the same level of the 4L station (9 o'clock position at the level of the carina) but distally. In fact it is identifiable between the aorta and pulmonary artery, but lateral to the ligamentum arteriosum; so distally in respect of the transducer. Although this station is often visible, it is not easy to sample it due to this position and interposition of the pulmonary artery/aorta. The larger ultrasonic window and better needle maneuverability of the EUS scope allows a better approach of this station.

Station 6 (para-aortic lymph nodes) 92, 93

Anatomy

- Upper border: Imaginary horizontal line drawn tangentially along the upper border of aortic arch.

- Lower border: lower border of the aortic arch.92,93

\section{Echoendoscopy}

Same endoscopic position of 4L and 5, or slightly above, in order to better visualize these nodes located on the outer aspect (anterior and lateral) of the ascending aorta and aortic arch. This station is are even more difficult sample

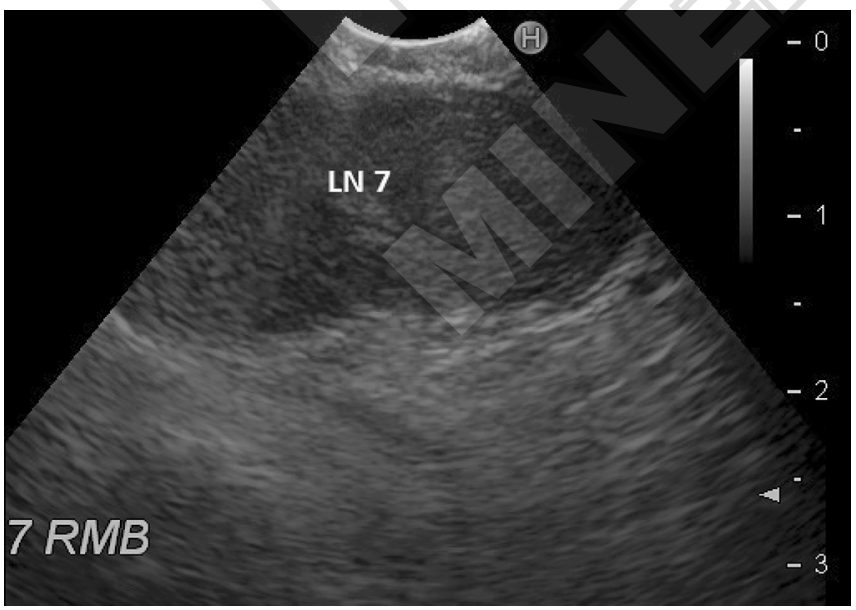

Figure 17.- Lymph node station 7, avoiding the aorta. ${ }^{52}$ Rarely is possible to pass above the aortic arch and to sample it and using a 25G-needle may be used. 52

Station 7 (subcarinal lymph nodes) ${ }^{92,93}$

\section{Anatomy}

- Upper border: carina.

- Lower border on the left: upper border of the left lower lobe bronchus.

- Lower border on the right: lower border of bronchus intermedius.

\section{Echoendoscopy}

Considering that this lymph node station is located inferior to the carina, it can be approached in the medial wall of either the right and the left main bronchus. The pulmonary artery and trunk are often visible anteriorly, and the esophagus is sometime visible distally. The borders of station seven are more clearly defined by bronchoscopic view than US landmarks.

This station is clearly identifiable with EUS/EUS-B. The left atrium and the pulmonary artery represent the EUS landmarks of the station. The nodes (especially the posterior group) are located in between of this structures; if not identified just slightly rotate the scope on the right at this level (Figure 17, 18).

Station 8 (paraesophageal lymph nodes) ${ }^{92,93}$

Anatomy

Adjacent to the esophageal wall but excluding the subcarinal (station 7) lymph nodes.

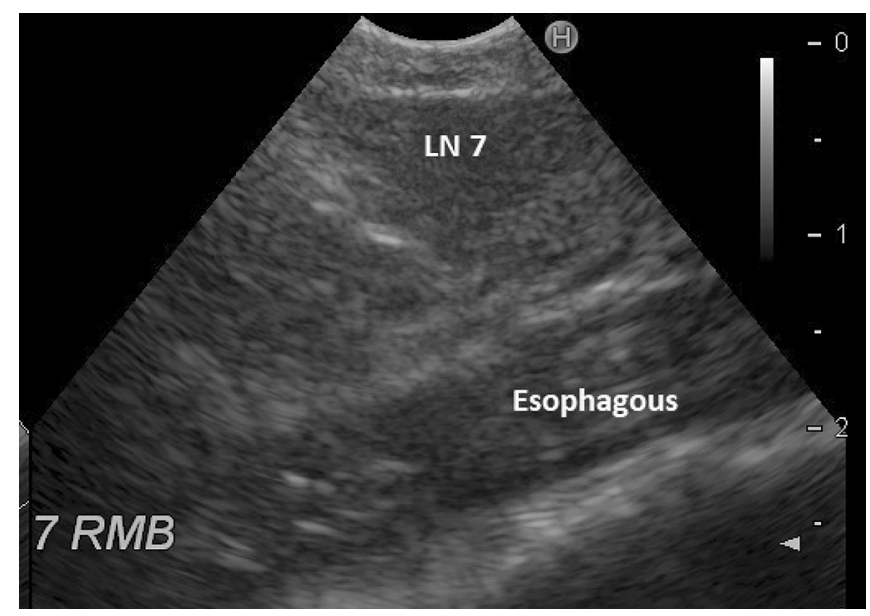

Figure 18.-Esophagous. 
The upper borders coincide with the lower border of station 7.

- Upper border on the left: upper border of the left lower lobe bronchus.

- Upper border on the right: lower border of bronchus intermedius.

- Lower border: the diaphragm.

\section{Echoendoscopy}

This station can be reached only by using the esophageal approach (EUS or EUS-B). It can be found identifying the right atrium and looking for its about this high, slightly rotating the scope on the right and/or the left.

Considering that both the upper border and the lower border of this station are defined by bronchial landmarks, it is impossible to identify these through EUS-(B) (Figure 19).

Station 9 (pulmonary ligament lymph nodes) $)^{92,93}$

\section{Anatomy}

These lymph nodes lie within the pulmonary ligament.

- Upper border: inferior pulmonary veins.

- Lower borders: diaphragm.

\section{Echoendoscopy}

The lymphnode station 9 can be visualized only through the esophageal approach (EUS or EUS-B). The scope should be positioned in order to identify the diaphragm on the left corner of the display and the right atrium on the right. At this level, the left pulmonary ligament lymph nodes (station 9) can be detected and sampled.

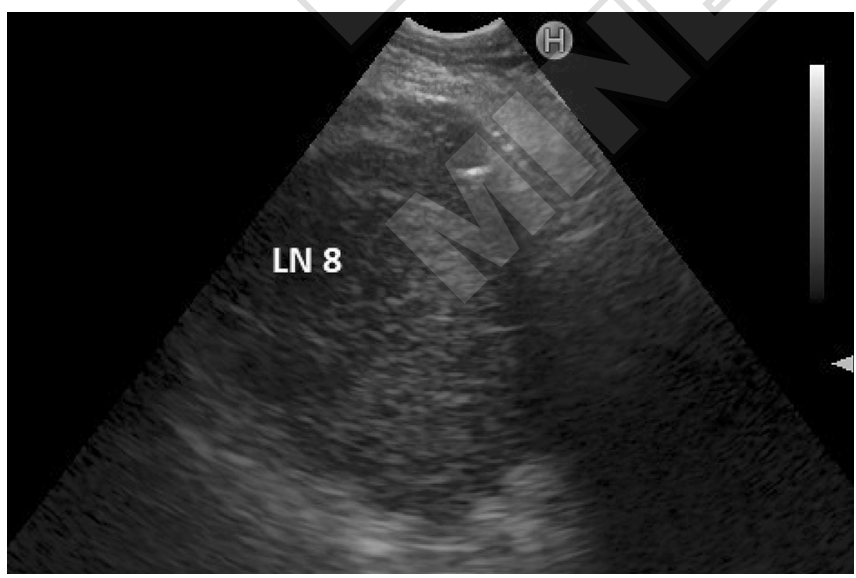

Figure 19.-Lymph node station 8.
Station 10 (hilar lymph nodes: adjacent to the mainstem bronchi and the hilar vessels) ${ }^{92,93}$

- $10 \mathrm{R}$

Anatomy

- Upper border: lower rim of the azygous vein;

- Lower border: interlobar region.

\section{Echoendoscopy}

This lymphnode station is located anterior to the right main bronchus about 12-1 o'clock position 1-2 intercartilage space below the carina.

Positioning the transducer at this level (anterior aspect of the right main bronchus) the nodes of this station can be reached beside the right pulmonary artery (Figure 20).

To easily find the upper border, the lower border of azygos vein should be identified at 2 o'clock position at the end of the trachea. To make sure that the individuated vessel is the azygos the point in which the azygos converges into the superior vena cava with a slightly anterior rotation of the scope should be found. The azygos vein distinguishes between 4R and 10R station and this is essential in the NSCLC staging.

The lower border (upper lobe carina) can be well identified through the endoscopic view.

\section{- $10 \mathrm{~L}$}

\section{Anatomy}

- Upper border: upper rim of left pulmonary artery.

- Lower border: interlobar regions.

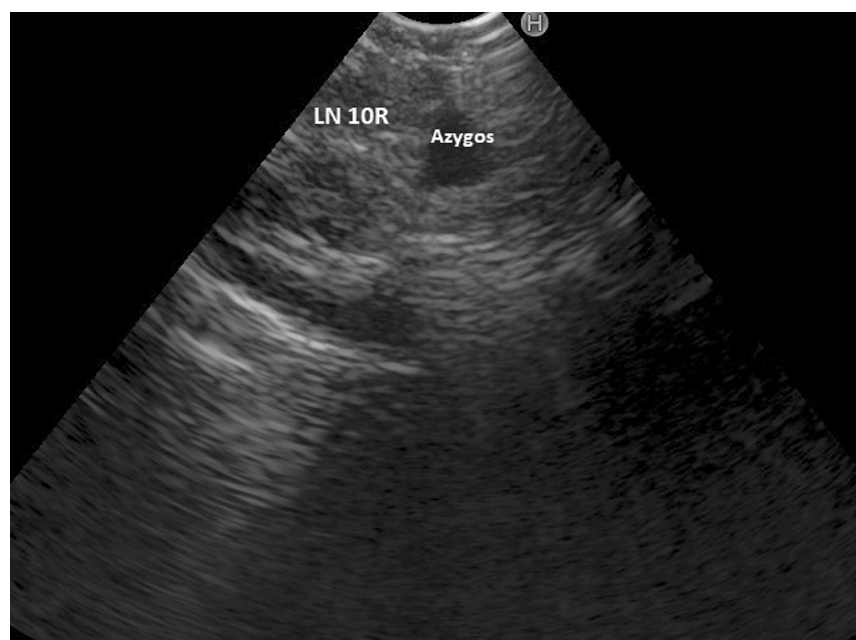

Figure 20.-Lymph node station 10R. 


\section{Echoendoscopy}

Positioning the EBUS transducer on the anterior/superior wall of the left main bronchus, just above the interlobar region, the station $10 \mathrm{~L}$ can be reached. Left pulmonary artery and pulmonary trunk are visible at this level and left atrium can be visualized more inferiorly.

The upper border (superior rim of pulmonary artery) is easily reachable through the ultrasound view of the micky mouse window (9 o'clock position at the level of the carina); whereas the lower border (upper lobe carina) is better identifiable through the endoscopic view.

Sometimes is not easy to reach a good US view of this station due to the not excellent adherence of the transducer on the left main bronchus wall (Figure 21).

Station $11 \mathbf{R}$ and L (interlobar lymph nodes) ${ }^{92,93}$

\section{Anatomy}

Located distal to the bifurcation of the mainstem bronchi (between the origins of lobar bronchi).

- 11Rs (11R superior)

The lymph nodes of this station are located between the bronchus intermedius and the right upper lobe. Positioning the EBUS transducer just below the spur of the upper lobe carina can be visualized the nodes with the right pulmonary artery superiorly and right pulmonary vein and pulmonary artery branch inferiorly. In fact this station are usually surrounded by the hylar vessel that can complicate the sample of the small nodes (Figure 22).

- 11Ri (11R inferior)

This station is located at the distal wall of the bronchus

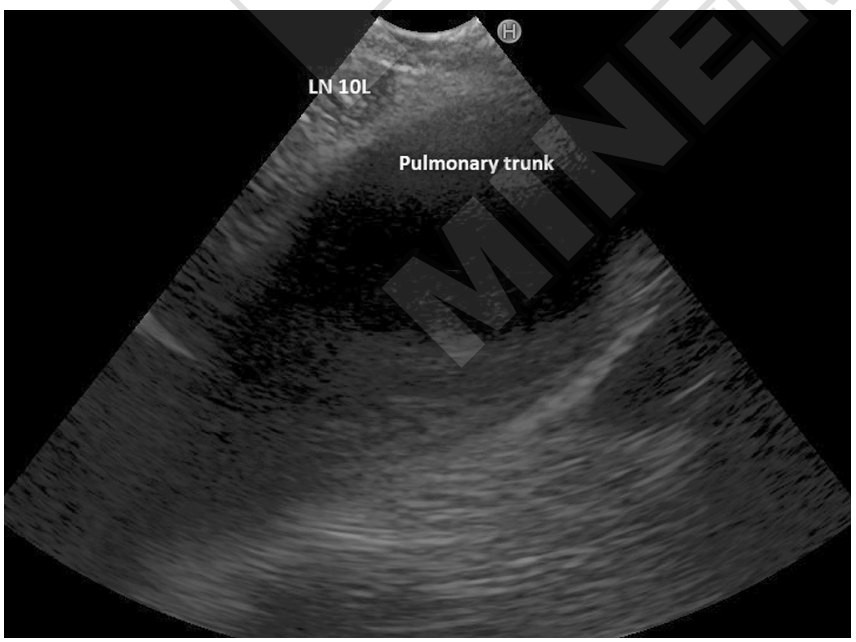

Figure 21.-Lymph node station 10L. intermedius, lateral to the right middle lobe. At this level is possible to recognize the right pulmonary vein leading to the left atrium superiorly, and the descending branch of pulmonary artery inferiorly.

- $11 \mathrm{~L}$

The lymph nodes of this station are located between the left upper lobe and the left lower lobe bronchus. Positioning the EBUS transducer just below the spur of the upper lobe carina the nodes of this station are visualized and the left pulmonary artery and the left pulmonary vein can be identified anteriorly (Figure 23).

Sometimes it is possible to visualize and sample station

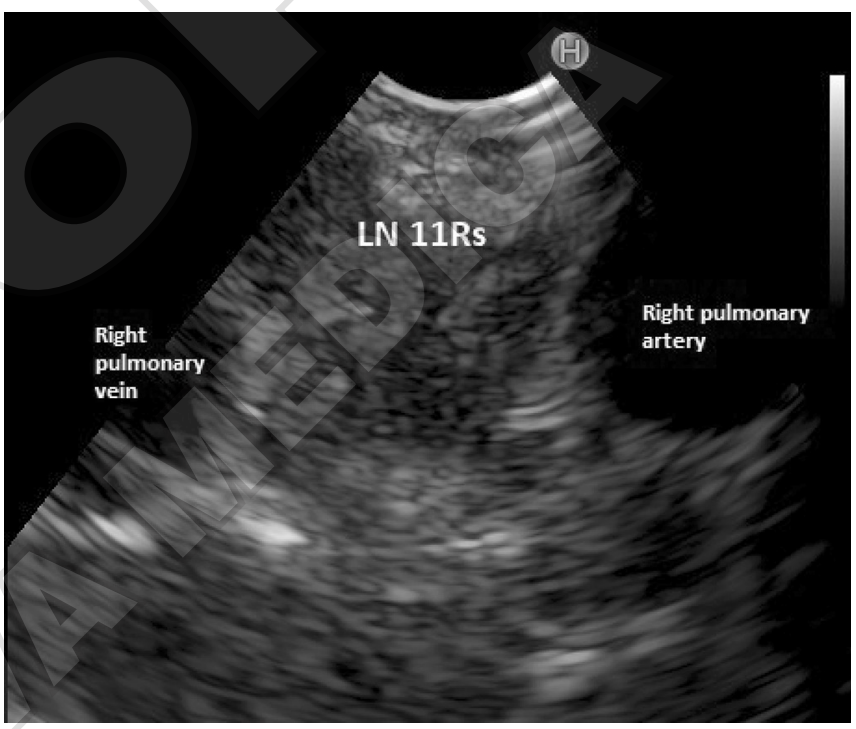

Figure 22.-Lymph node station 11Rs.

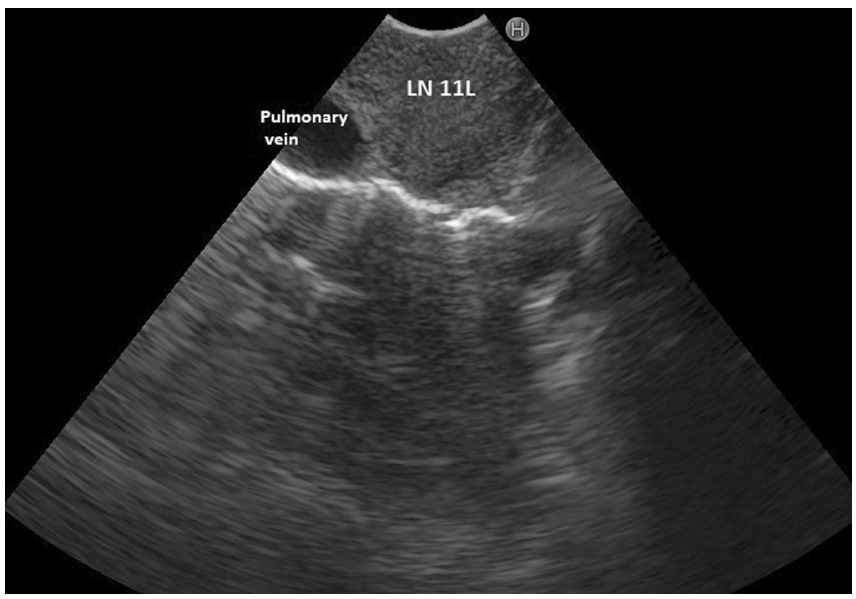

Figure 23.--Lymph node station 11L. 
12 and 13 almost exclusively if are located in the lower lobe with anatomical features that make that possible.

Distinguish between mediastinal lymph node stations could be challenging; but in some cases is essential perform an accurate staging and avoid under or overstaging.

Distinguishing station 1 from station 2 lymph nodes can be difficult when the lymph nodes are off midline and landmarks are not present. This is clinically important because stage N2 tumors can be misclassified as N3 or vice versa, but luckily these findings are very rare.

On the contrary, it is common to have to distinguish stations 4 from station 10 (both $\mathrm{R}$ and $\mathrm{L}$ ). This is important because $\mathrm{N} 1$ tumors can be misclassified as N2 or N2 can be misclassified as N3 (and vice versa). ${ }^{94}$. In fact if a tumor $(\mathrm{T})$ is located in the right lung, a 10R represent a N1 while the 4R a N2; if the tumor is the left lung the $10 \mathrm{R}$ will be a N3 while the $4 \mathrm{R}$ a N2. Obviously, different therapeutic options are reserved for this different $\mathrm{N}$ stage.

In this case is possible to use the US landmark represented by the lower rim of the azygos for the $4 \mathrm{R}$ and the upper rim of the pulmonary artery for the $4 \mathrm{~L}$. It could be easier for station $4 \mathrm{~L}$ in which generally the nodes of the respective stations are well separated by the pulmonary artery and the area to explore is smaller than $4 \mathrm{R}$ one, whereas, in relation to station $4 \mathrm{R}$, it is fundamental to find a smaller vessel as the azygos vein that can well distinguish 4R from 10R.

Classifying large lymph nodes that span more than 1 station can be difficult, but it is suggested to assign the station where the node predominantly reside. 92

\section{Theoretical and practical training}

The complexity of this advanced diagnostic procedure can make learning this procedure a difficult and time-consuming process, especially when a classical experiential teaching model is applied. 94,95

Indeed, the traditional apprenticeship model by which patients suffer the burden of technical training is currently ethically and legally questionable and exposes the supervisor, the trainees and the teaching hospital to several procedural and medical issues. For instance, trainee involvement significantly increased EBUS duration and the dose of local and general anesthesia used for the procedure and the diagnostic yield was lower when a trainee participated the exam. ${ }^{96}$ As a consequence, direct patient care would not uncommonly become overwhelming and a source of significant frustration and anxiety for both trainers and trainees. Furthermore, the learning curve may result longer than predicted due to poor availability of suited patients, or to the trainer's resistance to delegate a beginner to potentially risky procedures.

\section{Role of virtual reality simulators in training EBUS-TBNA}

In this context, the role of simulation is gaining interest and a raising amount of evidences confirm its role in training beginners.

Basically, two different simulation instruments exist providing low and high fidelity reproduction of anatomic structures and land mark, respectively. It is demonstrated that high fidelity simulation is not necessarily superior to low fidelity, especially in the training of basic bronchoscopic skills, ${ }^{97,}, 98$ in order to improve trainee's confidence and ability to maneuver the scope into the airways. Low fidelity simulation is usually cheap, with different models providing various degrees of realism. The purpose of this system is to emphasize psychomotor skills acquisition without distraction from the lack of knowledge of the anatomy in the early phases of training. ${ }^{99}$ There are relatively few studies assessing the impact of low-fidelity compared with high-fidelity simulation training on bronchoscopy skills, but a recent meta-analysis suggests that low-fidelity models may in fact be preferred in some situations ${ }^{100}$ so, at present, they are considered complementary. ${ }^{101}$ As a general rule, low-fidelity models may be more suitable for the most basic bronchoscopy tasks while simulation of more advanced procedures, such as EBUS and navigation bronchoscopy, are likely to be offered by high-fidelity systems. ${ }^{102}$ Indeed, high fidelity simulation adds several strengths to learning due to its realism that enables to recreate real life settings and to mimic every single procedural step. This is particularly evident in the EBUS-TBNA high fidelity simulators (i.e. endoscopy VR simulator [CAE Healthcare, Montreal, Quebec, Canada] and the GI-BRONCHMentor [Simbionix Ltd, Airport City, Israel]). Several studies have demonstrated that they are able to provide a relevant insight to beginners, shortens their learning curve, especially in its initial part ${ }^{103}$ and enable them to approach the real patient with a higher self-confidence and minimizing the risk of malpractice. Furthermore, considering the risk of damaging the scope deriving from a not proper use of needles and scopes, virtual simulation warrants also a relevant money sparing.

Another pivotal aspect of training through simulation, is represented by the realism of the environment in which the simulation takes place. For participants to fully engage 
in simulation, they need to willingly suspend their disbelief. One way of helping this is through the fidelity of the environment or simulation suite; making the suite appear like the clinical environment you are trying to emulate is very important.

In recently published review paper, EBUS simulator proved to accurately stratify trainees based on their baseline level of experience. Simulation-based training was demonstrated to be more efficient than the traditional apprenticeship model. Physical models and virtual reality simulators complement each other. Simulation-based education should be based on a mastery learning approach and structured as directed self-regulated learning in a distributed training programme.104 Importantly, skills acquired on a simulator could be transferred to real-world patients, this supporting a wider use of simulation. $6,103-107$

In conclusion simulator-based training of operators can potentially shorten the learning curve of EBUS and may be added to the training curriculum before operators perform EBUS on patients.

\section{Training of EUS-FNA and EUS-B-FNA}

There is a scarcity of evidence clarifying the modalities of training for transesophageal ultrasound FNA for the mediastinal staging of lung cancer, especially amongst nongastroenterologists. Although specific guidelines have been published, ${ }^{108,} 109$ they cannot be adequately applied for mediastinal staging, having been developed mainly to provide educational support for pancreatic and other abdominal samplings. Furthermore, it is not clear, but it is likely to be so, whether the learning curves of EUS and EUS-B-FNAs are different from each other, especially in Pulmonologists. Indeed, Konge et al. have recently documented that pulmonologists with knowledge of lung cancer staging and experience in bronchoscopy can rapidly improve their performance of EUS-FNA and reach a satisfying competence, even if not complete autonomy, after 20 supervised EUS-FNA procedures. However, acquisition of skills varies between individuals and in between consecutive procedures in the same trainee, so authors concluded that certification should be mandatory and based on assessment of performance of multiple cases. ${ }^{110}$ Virtual-reality simulators have been proposed as providers of objective and unbiased assessment, but no such simulators still exist for EUS-FNA of mediastinal structures and, furthermore, questions have been raised about the discriminative abilities of simulators ${ }^{111,112}$ and need to be clarified.
Future perspectives in EBUS-TBNA virtual reality simulation

To date, high fidelity simulation enables the beginner endoscopist to reach basic skillfulness and confidence to start real patient endoscopy without increased risk of significant impact on procedure proficiency.

Although extremely useful, this is still not enough. Further technologic improvement is highly desirable so that simulators may be soon able to provide specific, rarer and difficult to experience, clinical scenarios such as needle breakage, massive bleeding, severe hypoxemia, etc., the practitioner could be demanded and challenged to manage. This would allow, exactly like it happens for professional aircraft pilots, to experience emergency protocols that are very unlikely in real life practice but that, nonetheless, have to be approached in a confident and proper way.

\section{Hands-on practice: summary of resources} for training on endosonography

- Task trainer with low fidelity simulation: plastic and animal models, live animals and cadaver;

- Ultrasonic Bronchoscopy Simulator with EBUS and needle routinely used for patient;

- high fidelity with virtual reality to learn the anatomy and the manual dexterity required for bronchoscopy and sampling procedures, simulated clinical cases (BRONCH Mentor, BronchPilot EBUS-TBNA, BRONCH Express, EndoVR ${ }^{\mathrm{TM}}$ Interventional Simulator, Ultrasonic Bronchoscopy Simulator). The simulator is useful when EBUSSTAT score is $\geq 80 / 100$;

- Observe the procedure directly or with live. Main objective: "Pattern recognition": learn to recognize anatomic landmarks by observing the procedure when performed by an experienced colleague in the clinical setting or on a simulator.

- Perform EBUS under supervision. Main objectives:

- "Handling of the endoscope": learn to insert the endoscope and to produce the pictures, which is much more difficult than watching an experienced practitioner performing the procedure.

- "How to take biopsies": learn to position the transducer correctly and to use a sheet and the needle.

- Learn step by step, beginning from the six EBUS landmarks (Stations 4L, 7, 10L, 10R, 4R, Azygos vein).

- An EBUS-EUS training programme and certification in 3 step is available by European Respiratory society 
(ERS): theoretical teaching and simulation, active clinical observation, final assessment after 20 procedures, 3 videos (www.ersnet.org)

\section{Quantitative and qualitative assessment}

Quantitative assessment of competences has been proposed as a standard reference tool for many years. Yet, most of existing guidelines, still require a minimum number of EBUS-TBNA to be performed in order to certify trainee's proficiency and competence. 95,113 However, it is well known, how the identification of a fixed minimum number of performed procedures threshold is somehow arbitrary since an extreme variability exist in individual learning curves. A recently published study documented that learning curve of subjects practicing EBUS-TBNA directly on the patients may be quite long and up to 120 procedures may be required before diagnostic accuracy, sensitivity and specificity reach the highest levels. ${ }^{114}$ In a recent systematic review evaluating the EBUS-TBNA learning curves, 16 studies were analyzed and documented that the threshold numbers needed to attain proficiency in EBUS-TBNA varied from 10 to 100 in individual studies with a mean of 37-44 procedures. ${ }^{6}$

Furthermore, a learner-centric training model may be challenging due to limited exposure to novel technologies, work hour restrictions for trainees, lack of simulation equipment or facilities, and potential scarcity of skilled educators.

On these bases, the question of how properly warrant training should become pivotal so that physicians can be taught to the highest standards and patients can rely on the highest competency. Furthermore, the final assessment assigned to each trainee should not merely list the number of practical procedures performed, but rather provide a means of certifying the trainee's level of competence.

Indeed, the problem of unstructured and not standardized training programs is a key issue worldwide with large heterogeneity amongst countries and teaching centers, and a general lack of competence certification for both fellows and skilled professionals, whose maintenance of competences should be regularly assessed.

Different suggestions or requirements for determining competence are based on volume according to American College of Graduate Medical Education requirements and guidelines published by CHEST, the British Thoracic Society, and the American Thoracic Society/European Respiratory Society. $115-119$

But no conclusive consensus nor standardization has been reached yet. More recently, the American College of Chest Physician (ACCP) has published an expert panel report ${ }^{113}$ assessing the current state of training and, based on available evidences, to issue statements on how new EBUS training content and guidelines should be structured in the forthcoming future. Similarly, a report of the Consensus Conference on Training and Competence Standards for the Interventional Pulmonology Master Program in Italy has recently been made available. 120

For such a reason, the combined European Society of Gastrointestinal Endoscopy (ESGE), European Respiratory Society (ERS) and European Society of Thoracic Surgeons (ESTS) guidelines do not require any quantitative assessment anymore, but recommend that competency in EBUS-TBNA and EUS-(B)-FNA for staging lung cancer be determined using available validated assessment tools (Table III). 121

Whatever the assessment instrument is, qualitative learning assessment must necessarily pass through a step by step process including all the basic skills needed to complete and perform the whole EBUS-TBNA procedure:

TABLE III.-Summary of quantitative and qualitative assessment. ${ }^{119,120}$

\begin{tabular}{|c|c|}
\hline & $\begin{array}{l}\text { Number of procedures: } \\
\text { - (100 EBUS procedures according to } \\
\text { accreditation standards reported in Mullon et } \\
\text { al. })^{119} 50 \text { procedures, after at least } 100 \text { flexible } \\
\text { bronchoscopies and } 5 \text { TBNAs } \\
\text { - MCQ } \\
\text { - Case-based questionnaire } \\
\text { - DOPS (EBUS STAT, EBUS SAT) } \\
\text { - Assessment on patient: } \\
\text { - Balloon and needle set-up in all cases } \\
\text { - Ability to pass scope through vocal cords in } \pm 90 \% \\
\text { of cases } \\
\text { - Ability to image lymph node in question in } \pm 90 \% \\
\text { of cases } \\
\text { - Ability to pass TBNA needle through wall of } \\
\text { trachea/bronchus into node in } \pm 80 \% \\
\text { - Typical procedure time: } 30-40 \text { min } \\
\text { - ERS-EBUS Certification Methodology www. } \\
\text { ersnet.org based on verification of pre-requisites } \\
\text { and registration, theoretical interactive session, } \\
\text { simulation training, supervised training in home } \\
\text { institution, completion of } 20 \text { procedures and } 3 \\
\text { video procedures. }\end{array}$ \\
\hline $\begin{array}{l}\text { Outcome } \\
\text { assessment }\end{array}$ & $\begin{array}{l}\text { Diagnostic yield: Diagnostic samples containing } \\
\text { sufficient material for molecular testing required for } \\
\text { treatment guidance. } \\
\text { - Comparison with pathology staging } \\
\text { - Sensitivity for carcinoma in } \pm 75 \% \text { of cases } \\
\text { - Safety }(<1 \% \text { - bleeding, pneumothorax, } \\
\text { infections) }\end{array}$ \\
\hline $\begin{array}{l}\text { Competence } \\
\text { Maintenance (by } \\
\text { LOGBOOK) }\end{array}$ & $\begin{array}{l}\text { N. of procedures/year } \\
\cdot 20 / \text { year } \\
\text { - Re-evaluation }\end{array}$ \\
\hline
\end{tabular}


1) "Pattern recognition"; 2) "Handling of the endoscope, how to take biopsies." 122

To date, two different approaches have been validated in order to provide a qualitative assessment of competence in EBUS-TBNA. The first implies the use of dedicated questionnaires specifically developed to test the apprenticeship in EBUS-TBNA training. Basically, the two most widely available instruments are EBUS-STAT and EBUSAT. EBUS-STAT is an a 10-section unblinded, check list, test designed to evaluate the technical skill and relevant knowledge of a physician performing convex probe EBUSTBNA. Items $1-7$ test technical skills, whereas items 8-10 test CT scan and EBUS image recognition and correlation. It has been successfully validated and tested and can be used to classify EBUS-TBNA operators from novice to expert. ${ }^{123}$ Moreover, it has proved suitable for assessing skills amelioration during a simulation-based training, especially for novices and those with no previous experience. ${ }^{124}$ This approach suffers from intrinsic limitation of which both trainers and trainees should be aware of: first, non blinded raters often introduce bias in the ratings and limit the evidence of validity to a lower level according to the Oxford Centre for Evidence-based Medicine levels of evidence. ${ }^{125}$ It is very likely, in fact, that raters will be influenced by non-objectives factors, such as the appearance of the probands, their personal knowledge, or knowledge of previous experience or training; second, check-list designed tools only allows "black-or-white" assessments of the more complicated and multifaceted technical skills that constitute an EBUS procedure. As a consequence, this might lead to a "ceiling effect" where more experienced operators' improvement fails to be recognized. In other words, check-lists only register if a subpart of a procedure is performed, and not how well it is performed.

The second proposed questionnaire, the EBUS-SAT, is a 12-item tool in which each item is rated on a scale from one to five. Six items are designed to assess the knowledge of mediastinal anatomy by asking the operators to identify six anatomic landmarks (lymph node stations 4R, 4L, 7, $10 \mathrm{~L}$ or $11 \mathrm{~L}, 10 \mathrm{R}$ or $11 \mathrm{R}$ and azygos vein). Four items are related to the technical skills necessary to handle the scope and perform TBNA (insertion of the endoscope, positioning of the transducer, use of sheath and use of needle). ${ }^{111}$ Two items allow assessors to give their overall opinion on anatomic orientation and biopsy sampling. It allows for a blinded assessment of clinical EBUS-TBNA performance and, therefore, seems to be less influenced by external, subjective, sources of bias.

The third option, the use of a virtual reality simulator, is likely to overcome all the above mentioned limitations. First, it let the beginner free to practice safely and without supervision without any risk for patients and scopes; second, it provides a controlled, highly reproducible and standardized simulated settings and, finally, it allows to obtain number of performance metrics that can be used to objectively assess performance. Konge and colleagues have recently tested and validated a virtual reality simulation metric set and concluded that, although discriminative abilities of currently available high fidelity simulators should be enforced, after a proper test design, a credible standard setting and appropriate transfer studies, virtual reality simulators would represent a pivotal innovation in first line training of beginners. ${ }^{126}$ Indeed, skills acquired by high fidelity virtual reality simulation can be detected by using other evaluation tools such as the already described EBUS-STAT ${ }^{124}$ and EBUSSAT ${ }^{111}$ questionnaires.

In a recent study, Scarlata and co-workers were able to demonstrate that virtual reality simulation facilitates practical learning among practitioners, and EBUS-STAT questionnaire is capable of detecting these improvements. ${ }^{124}$

The Endoscopic Ultrasonography Assessment Tool (EUSAT) used in EUS-FNA for mediastinal staging has been proposed as a tool also in the respiratory medicine environment. A study by Konge et al. shows the EUSAT can distinguish operators' performances according to their level of experience, and the result appears to be reproducible. ${ }^{127}$ However, further research is needed to realize whether the different learning curves existing between GI endoscopists and bronchoscopists in EUS might be affecting the psycometric properties of this application.

Furthermore, it is likely that in the future the respiratory endoscopist will perform EUS mostly by using traditional linear EBUS or specifically developed "hybrid tracheobroncho-esophageal" instruments instead of the current, standard, EUS scope. It is unknown whether the EUSAT might be equally performed to measure proficiency in EUSB-FNA practitioners. Further research is needed to clarify this issue and, eventually, to develop dedicated tools.

In conclusion, it would be desirable for trainees to systematically have simulated training before commencing patient experience. But, there are difficulties, such as cost and accessibility, that have to be overcome. Furthermore, a technologic effort to expand current simulation platform is needed and future research should provide evidence and operational recommendation to address the best approach and warrant the highest level of education amongst practitioners. 


\section{References}

1. Hürter T, Hanrath P. Endobronchial sonography: feasibility and preliminary results. Thorax 1992;47:565-7.

2. Anantham D, Koh MS, Ernst A. Endobronchial ultrasound. Respir Med 2009; 103:1406-14.

3. Lee HS, Lee GK, Lee HS, Kim MS, Lee JM, Kim HY, et al. Real-time endobronchial ultrasound-guided transbronchial needle aspiration in mediastinal staging of non-small cell lung cancer: how many aspirations per target lymph node station? Chest 2008;134:368-74.

4. Herth FJ, Lunn W, Eberhardt R, Becker HD, Ernst A. Transbronchial versus transesophageal ultrasound-guided aspiration of enlarged mediastinal lymph nodes. Am J Respir Crit Care Med 2005;171:1164-7.

5. Ost DE, Ernst A, Lei X, Feller-Kopman D, Eapen GA, Kovitz KL, et al.; AQuIRE Bronchoscopy Registry. Diagnostic yield of endobronchial ultrasound-guided transbronchial needle aspiration: results of the AQuIRE Bronchoscopy Registry. Chest 2011;140:1557-66.

6. Sehgal IS, Dhooria S, Aggarwal AN, Agarwal R. Training and proficiency in endobronchial ultrasound-guided transbronchial needle aspiration: A systematic review. Respirology 2017;22:1547-57.

7. Rusch VW, Asamura H, Watanabe H, Giroux DJ, Rami-Porta R, Goldstraw P; Members of IASLC Staging Committee. The IASLC lung cancer staging project: a proposal for a new international lymph node map in the forthcoming seventh edition of the TNM classification for lung cancer. J Thorac Oncol 2009;4:568-77.

8. Murgu SD. Diagnosing and staging lung cancer involving the mediastinum. Chest 2015;147:1401-12

9. De Leyn P, Lardinois D, Van Schil PE, Rami-Porta R, Passlick B, Zielinski $\mathrm{M}$, et al. ESTS guidelines for preoperative lymph node staging for non-small cell lung cancer. Eur J Cardiothorac Surg 2007;32:1-8.

10. Silvestri GA, Gonzalez AV, Jantz MA, Margolis ML, Gould MK, Tanoue LT, et al. Methods for staging non-small cell lung cancer: Diagnosis and management of lung cancer, 3rd ed: American College of Chest Physicians evidence-based clinical practice guidelines. Chest 2013;143(Suppl):e211S-50S.

11. De Leyn P, Dooms C, Kuzdzal J, Lardinois D, Passlick B, Rami-Porta $\mathrm{R}$, et al. Preoperative mediastinal lymph node staging for non-small cell lung cancer: 2014 update of the 2007 ESTS guidelines. Transl Lung Cancer Res 2014;3:225-33.

12. Cerfolio RJ, Bryant AS, Eloubeidi MA. Routine mediastinoscopy and esophageal ultrasound fine-needle aspiration in patients with non-small cell lung cancer who are clinically N2 negative: a prospective study. Chest 2006;130:1791-5.

13. Fibla JJ, Molins L, Simon C, Perez J, Vidal G. The yield of mediastinoscopy with respect to lymph node size, cell type, and the location of the primary tumor. J Thorac Oncol 2006;1:430-3.

14. Lee PC, Port JL, Korst RJ, Liss Y, Meherally DN, Altorki NK. Risk factors for occult mediastinal metastases in clinical stage I non-small cell lung cancer. Ann Thorac Surg 2007;84:177-81.

15. Hishida T, Yoshida J, Nishimura M, Nishiwaki Y, Nagai K. Problems in the current diagnostic standards of clinical N1 non-small cell lung cancer. Thorax 2008; 63:526-31.

16. Watanabe S, Asamura H, Suzuki K, Tsuchiya R. Problems in diagnosis and surgical management of clinical N1 non-small cell lung cancer. Ann Thorac Surg 2005;79:1682-5.

17. Lebioda A, Makarewicz R, Małkowski B, Dancewicz M, Kowalewski J, Windorbska W. Measurement of primary tumor volume by PET-CT to evaluate risk of mediastinal nodal involvement in NSCLC patients with clinically negative N2 lymph nodes. Rep Pract Oncol Radiother 2013; 18:76-81.

18. Zhou Q, Suzuki K, Anami Y, Oh S, Takamochi K. Clinicopathologic features in resected subcentimeter lung cancer-status of lymph node metastases. Interact Cardiovasc Thorac Surg 2010;10:53-7.
19. Seok Y, Yang HC, Kim TJ, Lee KW, Kim K, Jheon S, et al. Frequency of lymph node metastasis according to the size of tumors in resected pulmonary adenocarcinoma with a size of $30 \mathrm{~mm}$ or smaller. J Thorac Oncol 2014;9:818-24.

20. Takizawa T, Terashima M, Koike T, Watanabe T, Kurita Y, Yokoyama $\mathrm{A}$, et al. Lymph node metastasis in small peripheral adenocarcinoma of the lung. J Thorac Cardiovasc Surg 1998;116:276-80.

21. Sánchez de Cos J, Hernández JH, López MF, Sánchez SP, Gratacós AR, Porta RR; Sociedad Española Neumología y Cirugía Torácica. SEPAR guidelines for lung cancer staging. Arch Bronconeumol 2011;47:454-65.

22. Zhou X, Chen R, Huang G, Liu J. Potential clinical value of PET/CT in predicting occult nodal metastasis in T1-T2N0M0 lung cancer patients staged by PET/CT. Oncotarget 2017;8:82437-45.

23. Su M, Li Y, Li F, Li L, Tian R. Risk factors for N2 metastasis in patients with non-small-cell lung cancer: multivariate analyses of $18 \mathrm{~F}-\mathrm{FDG}$ PET/CT data. Nucl Med Commun 2014;35:916-21.

24. Micames CG, McCrory DC, Pavey DA, Jowell PS, Gress FG. Endoscopic ultrasound-guided fine-needle aspiration for non-small cell lung cancer staging: A systematic review and metaanalysis. Chest 2007; 131:539-48.

25. Gu P, Zhao YZ, Jiang LY, Zhang W, Xin Y, Han BH. Endobronchial ultrasound-guided transbronchial needle aspiration for staging of lung cancer: a systematic review and meta-analysis. Eur J Cancer 2009;45:1389-96.

26. Adams K, Shah PL, Edmonds L, Lim E. Test performance of endobronchial ultrasound and transbronchial needle aspiration biopsy for mediastinal staging in patients with lung cancer: systematic review and meta-analysis. Thorax 2009;64:757-62.

27. Chandra S, Nehra M, Agarwal D, Mohan A. Diagnostic accuracy of endobronchial ultrasound-guided transbronchial needle biopsy in mediastinal lymphadenopathy: a systematic review and meta-analysis. Respir Care 2012;57:384-91.

28. Zhang R, Ying K, Shi L, Zhang L, Zhou L. Combined endobronchial and endoscopic ultrasound-guided fine needle aspiration for mediastinal lymph node staging of lung cancer: a meta-analysis. Eur J Cancer 2013;49:1860-7.

29. Kinsey CM, Arenberg DA. Endobronchial ultrasound-guided transbronchial needle aspiration for non-small cell lung cancer staging. Am J Respir Crit Care Med 2014; 189:640-9.

30. Dhooria S, Aggarwal AN, Gupta D, Behera D, Agarwal R. Utility and Safety of Endoscopic Ultrasound With Bronchoscope-Guided Fine-Needle Aspiration in Mediastinal Lymph Node Sampling: Systematic Review and Meta-Analysis. Respir Care 2015;60:1040-50.

31. Sharples LD, Jackson C, Wheaton E, Griffith G, Annema JT, Dooms $\mathrm{C}$, et al. Clinical effectiveness and cost-effectiveness of endobronchial and endoscopic ultrasound relative to surgical staging in potentially resectable lung cancer: results from the ASTER randomised controlled trial. Health Technol Assess 2012;16:1-75, iii-iv.

32. Annema JT, van Meerbeeck JP, Rintoul RC, Dooms C, Deschepper E, Dekkers OM, et al. Mediastinoscopy vs endosonography for mediastinal nodal staging of lung cancer: a randomized trial. JAMA 2010;304:2245-52.

33. Bousema JE, Dijkgraaf MG, Papen-Botterhuis NE, Schreurs HW, Maessen JG, van der Heijden EH, et al.; MEDIASTrial study group. MEDIASTinal staging of non-small cell lung cancer by endobronchial and endoscopic ultrasonography with or without additional surgical mediastinoscopy (MEDIASTrial): study protocol of a multicenter randomised controlled trial. BMC Surg 2018;18:27.

34. Ceron L, Michieletto L, Zamperlin A, Mancino L. The Challenge of Mediastinal Staging. Eur Oncol Haematol 2011;7:31-5.

35. Herth FJ, Ernst A, Eberhardt R, Vilmann P, Dienemann H, Krasnik M. Endobronchial ultrasound-guided transbronchial needle aspiration of lymph nodes in the radiologically normal mediastinum. Eur Respir J 2006;28:910-4

36. Herth FJ, Eberhardt R, Krasnik M, Ernst A. Endobronchial ultra- 
sound-guided transbronchial needle aspiration of lymph nodes in the radiologically and positron emission tomography-normal mediastinum in patients with lung cancer. Chest 2008;133:887-91.

37. Szlubowski A, Zieliński M, Soja J, Annema JT, Sośnicki W, Jakubiak $\mathrm{M}$, et al. A combined approach of endobronchial and endoscopic ultrasound-guided needle aspiration in the radiologically normal mediastinum in non-small-cell lung cancer staging - a prospective trial. Eur J Cardiothorac Surg 2010;37:1175-9.

38. Ong P, Grosu H, Eapen GA, Rodriguez M, Lazarus D, Ost D, et al. Endobronchial ultrasound-guided transbronchial needle aspiration for systematic nodal staging of lung cancer in patients with N0 disease by computed tomography and integrated positron emission tomographycomputed tomography. Ann Am Thorac Soc 2015;12:415-9.

39. Shingyoji M, Nakajima T, Yoshino M, Yoshida Y, Ashinuma H, Itakura $\mathrm{M}$, et al. Endobronchial ultrasonography for positron emission tomography and computed tomography-negative lymph node staging in non-small cell lung cancer. Ann Thorac Surg 2014;98:1762-7.

40. Dooms C, Tournoy KG, Schuurbiers O, Decaluwe H, De Ryck F, Verhagen A, et al. Endosonography for mediastinal nodal staging of clinical N1 non-small cell lung cancer: a prospective multicenter study. Chest 2015;147:209-15.

41. El-Osta H, Jani P, Mansour A, Rascoe P, Jafri S. Endobronchial Ultrasound for Nodal Staging of Patients with Non-Small-Cell Lung Cancer with Radiologically Normal Mediastinum. A Meta-Analysis. Ann Am Thorac Soc 2018;15:864-74.

42. Kitami A, Sano F, Ohashi S, Suzuki K, Uematsu S, Suzuki T, et al The Usefulness of Positron-Emission Tomography Findings in the Management of Anterior Mediastinal Tumors. Ann Thorac Cardiovasc Surg $2017 ; 23: 26-30$

43. Mehra M, Tamhane A, Eloubeidi MA. EUS-guided FNA combined with flow cytometry in the diagnoses of suspected or recurrent intrathoracic or retroperitoneal lymphoma. Gastrointest Endosc 2005;62:508-13.

44. Al-Haddad M, Savabi MS, Sherman S, McHenry L, Leblanc J, Cramer $\mathrm{H}$, et al. Role of endoscopic ultrasound-guided fine-needle aspiration with flow cytometry to diagnose lymphoma: a single center experience. J Gastroenterol Hepatol 2009;24:1826-33.

45. Dumonceau JM, Deprez PH, Jenssen C, Iglesias-Garcia J, Larghi A Vanbiervliet $\mathrm{G}$, et al. Indications, results, and clinical impact of endoscopic ultrasound (EUS)-guided sampling in gastroenterology: European Society of Gastrointestinal Endoscopy (ESGE) Clinical Guideline - Updated January 2017. Endoscopy 2017;49:695-714.

46. Gandotra S, Dotson T, Lamar Z, Bellinger C. Endobronchial Ultrasound Transbronchial Needle Aspiration for the Diagnosis of Lymphoma J Bronchology Interv Pulmonol 2018;25:97-102.

47. Tyan C, Patel P, Czarnecka K, Gompelmann D, Eberhardt R, Fortin M, et al. Flexible 19-Gauge Endobronchial Ultrasound-Guided Transbronchial Needle Aspiration Needle: first Experience. Respiration 2017:94:52-7.

48. Tremblay A, Stather DR, MacEachern P, Khalil M, Field SK. A randomized controlled trial of standard vs endobronchial ultrasonographyguided transbronchial needle aspiration in patients with suspected sarcoidosis. Chest 2009;136:340-6.

49. Agarwal R, Srinivasan A, Aggarwal AN, Gupta D. Efficacy and safety of convex probe EBUS-TBNA in sarcoidosis: a systematic review and meta-analysis. Respir Med 2012;106:883-92.

50. Chee A, Khalil M, Stather DR, MacEachern P, Field SK, Tremblay A. Cytologic assessment of endobronchial ultrasound-guided transbronchial needle aspirates in sarcoidosis. J Bronchology Interv Pulmonol 2012;19:24-8.

51. von Bartheld MB, Veseliç-Charvat M, Rabe KF, Annema JT. Endoscopic ultrasound-guided fine-needle aspiration for the diagnosis of sarcoidosis. Endoscopy 2010;42:213-7.

52. Jenssen C, Annema JT, Clementsen P, Cui XW, Borst MM, Dietrich $\mathrm{CF}$. Ultrasound techniques in the evaluation of the mediastinum, part 2: mediastinal lymph node anatomy and diagnostic reach of ultrasound techniques, clinical work up of neoplastic and inflammatory mediastinal lymphadenopathy using ultrasound techniques and how to learn mediastinal endosonography. J Thorac Dis 2015;7:E439-58.

53. Wahidi MM, Herth F, Yasufuku K, Shepherd RW, Yarmus L, Chawla M, et al. Technical Aspects of Endobronchial Ultrasound-Guided Transbronchial Needle Aspiration: CHEST Guideline and Expert Panel Report. Chest 2016;149:816-35.

54. van der Heijden EH, Casal RF, Trisolini R, Steinfort DP, Hwangbo B Nakajima T, et al.; World Association for Bronchology and Interventional Pulmonology, Task Force on Specimen Guidelines. Guideline for the acquisition and preparation of conventional and endobronchial ultrasoundguided transbronchial needle aspiration specimens for the diagnosis and molecular testing of patients with known or suspected lung cancer. Respiration 2014;88:500-17.

55. Aswanetmanee $P$, Limsuwat $C$, Kabach $M$, Alraiyes AH, Kheir F. The role of sedation in endobronchial ultrasound-guided transbronchial needle aspiration: systematic review. Endosc Ultrasound 2016;5:300-6.

56. Yarmus LB, Akulian JA, Gilbert C, Mathai SC, Sathiyamoorthy S, Sahetya $\mathrm{S}$, et al. Comparison of moderate versus deep sedation for endobronchial ultrasound transbronchial needle aspiration. Ann Am Thorac Soc 2013;10:121-6.

57. DePew ZS, Edell ES, Midthun DE, Mullon JJ, Bungum AO, Decker PA, et al.; Mayo Pulmonary Procedural Group. Endobronchial ultrasoundguided transbronchial needle aspiration: determinants of sampling adequacy. J Bronchology Interv Pulmonol 2012;19:271-6.

58. Ando K, Ohkuni Y, Fukazawa M, Abe M, Takeshi A, Kaneko N. Sedation with meperidine for endobronchial ultrasound $\square$ guided transbronchial needle aspiration. J Bronchology Interv Pulmonol 2010;17:329-33.

59. Eapen GA, Shah AM, Lei X, Jimenez CA, Morice RC, Yarmus L, et al.; American College of Chest Physicians Quality Improvement Registry, Education, and Evaluation (AQuIRE) Participants. Complications, consequences, and practice patterns of endobronchial ultrasound-guided transbronchial needle aspiration: results of the AQuIRE registry. Chest 2013;143:1044-53.

60. Öztas S, Aka Aktürk Ü, Alpay LA, Meydan B, Ogün H, Taylan M, et al. A comparison of propofol-midazolam and midazolam alone for sedation in endobronchial ultrasound-guided transbronchial needle aspiration a retrospective cohort study. Clin Respir J 2017;11:935-41.

61. Casal RF, Lazarus DR, Kuhl K, Nogueras-González G, Perusich S, Green LK, et al. Randomized trial of endobronchial ultrasound-guided transbronchial needle aspiration under general anesthesia versus moderate sedation. Am J Respir Crit Care Med 2015;191:796-803.

62. Nakajima T, Yasufuku K. The techniques of endobronchial ultrasound-guided transbronchial needle aspiration. Innovations (Phila) 2011;6:57-64.

63. Colella S, Vilmann P, Konge L, Clementsen PF. Endoscopic ultrasound in the diagnosis and staging of lung cancer. Endosc Ultrasound $2014 ; 3: 205-12$

64. Colt H. The bronchoscopy education project. Training Manual, Subject (Part II): Endobronchial Ultrasound Bronchoscopy Competency Program. Bronchoscopy international [Internet]. Available from https://www pdffiller.com/jsfiller-desk4/?projectId $=234716743 \&$ expId $=4094 \& \operatorname{expBra}$ $\mathrm{nch}=3 \#$ a52912eac91247a5924997e446712a6a [cited 2018, Nov 7].

65. Oki M, Saka H, Ando M, Nakashima H, Shiraki A, Murakami Y, et al. How Many Passes Are Needed for Endobronchial Ultrasound-Guided Transbronchial Needle Aspiration for Sarcoidosis? A Prospective Multicenter Study. Respiration 2018;95:251-7.

66. Sun J, Yang H, Teng J, Zhang J, Zhao H, Garfield DH, et al. Determining factors in diagnosing pulmonary sarcoidosis by endobronchial ultrasound-guided transbronchial needle aspiration. Ann Thorac Surg 2015;99:441-5.

67. Yarmus L, Akulian J, Gilbert C, Feller-Kopman D, Lee HJ, Zarogoulidis $\mathrm{P}$, et al. Optimizing endobronchial ultrasound for molecular analysis. How many passes are needed? Ann Am Thorac Soc 2013;10:636-43.

68. Casal RF, Staerkel GA, Ost D, Almeida FA, Uzbeck MH, Eapen GA, 
et al. Randomized clinical trial of endobronchial ultrasound needle biopsy with and without aspiration. Chest 2012;142:568-73.

69. Boonsarngsuk V, Pongtippan A, Juthakarn S. The effect of aspiration pressure over endobronchial ultrasound-guided transbronchial needle aspiration on the diagnosis of intrathoracic lymphadenopathies. Ha 2013;191:435-40.

70. Shiroyama T, Okamoto N, Suzuki H, Tamiya M, Yamadori T, Morishita $\mathrm{N}$, et al. Usefulness of high suction pressure for sufficient tissue collection during endobronchial ultrasound guided transbronchial needle aspiration. PLoS One 2013;8:e82787.

71. Yarmus LB, Akulian J, Lechtzin N, Yasin F, Kamdar B, Ernst A, et al.; American College of Chest Physicians Quality Improvement Registry, Education, and Evaluation (AQuIRE) Participants. Comparison of 21-gauge and 22-gauge aspiration needle in endobronchial ultrasoundguided transbronchial needle aspiration: results of the American College of Chest Physicians Quality Improvement Registry, Education, and Evaluation Registry. Chest 2013;143:1036-43.

72. Nakajima T, Yasufuku K, Takahashi R, Shingyoji M, Hirata T, Itami $\mathrm{M}$, et al. Comparison of 21-gauge and 22-gauge aspiration needle during endobronchial ultrasound-guided transbronchial needle aspiration. Respirology 2011;16:90-4

73. Saji J, Kurimoto N, Morita K, Nakamura M, Inoue T, Nakamura H, et al. Comparison of 21-gauge and 22-gauge Needles for Endobronchial Ultrasound-Guided Transbronchial Needle Aspiration of Mediastinal and Hilar Lymph Nodes. J Bronchology Interv Pulmonol 2011;18:239-46.

74. Oki M, Saka H, Kitagawa C, Kogure Y, Murata N, Ichihara S, et al Randomized study of 21-gauge versus 22-gauge endobronchial ultrasound-guided transbronchial needle aspiration needles for sampling histology specimens. J Bronchology Interv Pulmonol 2011;18:306-10.

75. Dooms C, Vander Borght S, Yserbyt J, Testelmans D. wauters E, Nacckaerts K, Vansteenkiste J, Verbeken E, Weynand B. A Randomized Clinical Trial of Flex 19G Needles versus 22G Needles for Endobronchial Ultrasonography in Suspected Lung Cancer. Respiration. $2018 ; \bullet \bullet \bullet: 1-8$

76. Scholten EL, Semaan R, Illei P, Mallow C, Arias S, Feller-Kopman $\mathrm{D}$, et al. Stylet Use Does Not Improve Diagnostic Outcomes in Endobronchial Ultrasonographic Transbronchial Needle Aspiration: A Randomized Clinical Trial. Chest 2017;151:636-42.

77. Mehta AC, Wang KP. Teaching conventional transbronchial needle aspiration. A continuum. Ann Am Thorac Soc 2013;10:685-9.

78. Bulman W, Saqi A, Powell CA. Acquisition and processing of endobronchial ultrasound-guided transbronchial needle aspiration specimens in the era of targeted lung cancer chemotherapy. Am J Respir Crit Care Med 2012;185:606-11.

79. Yung RC, Otell S, Illei P, Clark DP, Feller-Kopman D, Yarmus L, et al. Improvement of cellularity on cell block preparations using the so-called tissue coagulum clot method during endobronchial ultrasound-guided transbronchial fine-needle aspiration. Cancer Cytopathol 2012;120:185-95.

80. Amin EN, Russell CD, Shilo K, Islam S, Wood KL. Diagnostic value of blood clot core during endobronchial ultrasound-guided transbronchial needle aspirate. Hai 2013;191:305-9.

81. Sehgal IS, Dhooria S, Aggarwal AN, Agarwal R. Impact of Rapid On-Site Cytological Evaluation (ROSE) on the Diagnostic Yield of Transbronchial Needle Aspiration During Mediastinal Lymph Node Sampling: Systematic Review and Meta-Analysis. Chest 2018;153:929-38.

82. Oki M, Saka H, Kitagawa C, Kogure Y, Murata N, Adachi T, et al. Rapid on-site cytologic evaluation during endobronchial ultrasound-guided transbronchial needle aspiration for diagnosing lung cancer: a randomized study. Respiration 2013;85:486-92.

83. Trisolini R, Cancellieri A, Tinelli C, Paioli D, Scudeller L, Casadei GP, et al. Rapid on-site evaluation of transbronchial aspirates in the diagnosis of hilar and mediastinal adenopathy: a randomized trial. Chest 2011;139:395-401.

84. Madan K, Dhungana A, Mohan A, Hadda V, Jain D, Arava S, et al
Conventional transbronchial needle aspiration versus endobronchial ultrasound-guided transbronchial needle aspiration, with or without rapid onsite evaluation, for the diagnosis of sarcoidosis: a randomized controlled trial. J Bronchology Interv Pulmonol 2017;24:48-58.

85. Fujiwara T, Yasufuku K, Nakajima T, Hadda V, Chiyo M, Yoshida S, et al. The Utility of Sonographic Features During Endobronchial Ultrasound-Guided Transbronchial Needle Aspiration for Lymph Node Staging in Patients With Lung Cancer. A Standard Endobronchial Ultrasound Image Classifi cation System. Chest 2010;138:641-7.

86. Nakajima T, Anayama T, Shingyoji M, Kimura H, Yoshino I, Yasufuku K. Vascular Image Patterns of Lymph Nodes for the Prediction of Metastatic Disease During EBUS-TBNA for Mediastinal Staging of Lung Cancer. J Thorac Oncol 2012;7:1009-14.

87. Rozman A, Malovrh MM, Adamic K, Subic T, Kovac V, Flezar M. Endobronchial ultrasound elastography strain ratio for mediastinal lymph node diagnosis. Radiol Oncol 2015;49:334-40.

88. Izumo T, Sasada S, Chavez C, Matsumoto Y, Tsuchida T. Endobronchial ultrasound elastography in the diagnosis of mediastinal and hilar lymph nodes. Jpn J Clin Oncol 2014;44:956-62.

89. Nakajima T, Inage T, Sata $Y$, Morimoto J, Tagawa T, Suzuki H, et al. Elastography for Predicting and Localizing Nodal Metastases during Endobronchial Ultrasound. Respiration 2015;90:499-506.

90. Carlsen JF, Ewertsen C, Săftoiu A, Lönn L, Nielsen MB. Accuracy of visual scoring and semi-quantification of ultrasound strain elastographya phantom study. PLoS One 2014;9:e88699.

91. Dietrich CF, Jenssen C, Herth FJ. Endobronchial ultrasound elastography. Endosc Ultrasound 2016;5:233-8.

92. Jawad H, Chung JH. Pulmonologist's Road Map to Mediastinal Lymph Node Imaging. Clin Chest Med 2018;39:17-30.

93. Shah P. Atlas of Flexible Bronchoscopy. CRC Press, 30 dic 2011.

94. Folch E, Majid A. Point: are $>50$ supervised procedures required to develop competency in performing endobronchial ultrasound-guided transbronchial needle aspiration for mediastinal staging? Yes. Chest 2013;143:888-91.

95. Wahidi MM, Hulett C, Pastis N, Shepherd RW, Shofer SL, Mahmood $\mathrm{K}$, et al. Learning experience of linear endobronchial ultrasound among pulmonary trainees. Chest 2014; 145:574-8.

96. Nguyen S, Ferland N, Beaudoin S, Martel S, Simon M, Laberge F, et al. Influence of trainee involvement on procedural characteristics for linear endobronchial ultrasound. Thorac Cancer 2017;8:517-22.

97. Martin KM, Larsen PD, Segal R, Marsland CP. Effective nonanatomical endoscopy training produces clinical airway endoscopy proficiency. Anesth Analg 2004;99:938-44.

98. Marsland CP, Robinson BJ, Chitty CH, Guy BJ. Acquisition and maintenance of endoscopic skills: developing an endoscopic dexterity training system for anesthesiologists. J Clin Anesth 2002;14:615-9.

99. Agrò F, Sena F, Lobo E, Scarlata S, Dardes N, Barzoi G. The Dexter Endoscopic Dexterity Trainer improves fibreoptic bronchoscopy skills: preliminary observations. Can J Anaesth 2005;52:215-6.

100. Kennedy CC, Maldonado F, Cook DA. Simulation-based bronchoscopy training: systematic review and meta-analysis. Chest 2013;144:183-92.

101. Lee HJ, Coleman B, Lerner AD, Feller-Kopman D, Semaan R, Frimpong B, et al. Procedural Learning Perspectives of Pulmonary Fellows and Practitioners. J Bronchology Interv Pulmonol 2017;24:200-5.

102. Fielding DI, Maldonado F, Murgu S. Achieving competency in bronchoscopy: challenges and opportunities. Respirology 2014;19:472-82.

103. Konge L, Clementsen PF, Ringsted C, Minddal V, Larsen KR, Annema JT. Simulator training for endobronchial ultrasound: a randomised controlled trial. Eur Respir J 2015;46:1140-9.

104. Naur TM, Nilsson PM, Pietersen PI, Clementsen PF, Konge L. Simulation-Based Training in Flexible Bronchoscopy and Endobronchial Ultrasound-Guided Transbronchial Needle Aspiration (EBUS-TBNA): A Systematic Review. Respiration 2017;93:355-62. 
105. Fuso L, Varone F, Magnini D, Pecoriello A, Montemurro G, Angeletti $\mathrm{G}$, et al. Influence of the Learning Effect on the Diagnostic Yield of Endobronchial Ultrasound-guided Transbronchial Needle Aspiration of Mediastinal and Hilar Lymph Nodes. J Bronchology Interv Pulmonol 2017;24:193-9.

106. Naur TM, Konge L, Nayahangan LJ, Clementsen PF. Training and certification in endobronchial ultrasound-guided transbronchial needle aspiration. J Thorac Dis 2017;9:2118-23.

107. Stather DR, Chee A, MacEachern P, Dumoulin E, Hergott CA, Gelberg $\mathrm{J}$, et al. Endobronchial ultrasound learning curve in interventional pulmonary fellows. Respirology 2015;20:333-9.

108. Polkowski $M$, Larghi $A$, Weynand $B$, Boustière $C$, Giovannini $M$, Pujol B, et al.; European Society of Gastrointestinal Endoscopy (ESGE). Learning, techniques, and complications of endoscopic ultrasound (EUS)guided sampling in gastroenterology: European Society of Gastrointestinal Endoscopy (ESGE) Technical Guideline. Endoscopy 2012;44:190-206.

109. Eisen GM, Dominitz JA, Faigel DO, Goldstein JA, Petersen BT, Raddawi HM, et al.; American Society for Gastrointestinal Endoscopy. Guidelines for credentialing and granting privileges for endoscopic ultrasound. Gastrointest Endosc 2001;54:811-4.

110. Konge L, Annema J, Vilmann P, Clementsen P, Ringsted C. Transesophageal ultrasonography for lung cancer staging: learning curves of pulmonologists. J Thorac Oncol 2013;8:1402-8.

111. Konge L, Arendrup H, von Buchwald C, Ringsted C. Using performance in multiple simulated scenarios to assess bronchoscopy skills. Respiration 2011;81:483-90.

112. Grantcharov TP, Carstensen L, Schulze S. Objective assessment of gastrointestinal endoscopy skills using a virtual reality simulator. JSLS 2005;9:130-3.

113. Ernst A, Wahidi MM, Read CA, Buckley JD, Addrizzo-Harris DJ, Shah PL, et al. Adult Bronchoscopy Training: Current State and Suggestions for the Future: CHEST Expert Panel Report. Chest 2015;148:321-32.

114. Lin CK, Lai CL, Chang LY, Wen YF, Ho CC. Learning curve and advantages of endobronchial ultrasound-guided transbronchial needle aspiration as a first-line diagnostic and staging procedure. Thorac Cancer 2018;9:75-82.

115. Farr A, Clementsen P, Herth F, Konge L, Rohde G, Dowsland S, et al. Endobronchial ultrasound: launch of an ERS structured training programme. Breathe (Sheff) 2016;12:217-20

116. Ernst A, Silvestri GA, Johnstone D; American College of Chest Physicians. Interventional pulmonary procedures: Guidelines from the American College of Chest Physicians. Chest 2003;123:1693-717.
117. Bolliger CT, Mathur PN, Beamis JF, Becker HD, Cavaliere S, Colt H, et al.; European Respiratory Society/American Thoracic Society. ERS/ATS statement on interventional pulmonology. Eur Respir J 2002;19:356-73.

118. Lamb CR, Feller-Kopman D, Ernst A, Simoff MJ, Sterman DH, Wahidi MM, et al. An approach to interventional pulmonary fellowship training. Chest 2010;137:195-9.

119. Mullon JJ, Burkart KM, Silvestri G, Hogarth DK, Almeida F, Berkowitz D, et al. Interventional Pulmonology Fellowship Accreditation Standards: Executive Summary of the Multisociety Interventional Pulmonology Fellowship Accreditation Committee. Chest 2017;151:1114-21.

120. Corbetta L, Patelli M. Executive Summary of Training and Competence Standards for the Interventional Pulmonology Master Program in Italy. J Bronchology Interv Pulmonol 2018;25:6-8

121. Vilmann P, Clementsen PF, Colella S, Siemsen M, De Leyn P, Dumonceau JM, et al. Combined endobronchial and esophageal endosonography for the diagnosis and staging of lung cancer: European Society of Gastrointestinal Endoscopy (ESGE) Guideline, in cooperation with the European Respiratory Society (ERS) and the European Society of Thoracic Surgeons (ESTS). Endoscopy 2015;47:545-59.

122. Konge L, Colella S, Vilmann P, Clementsen PF. How to learn and to perform endoscopic ultrasound and endobronchial ultrasound for lung cancer staging: A structured guide and review. Endosc Ultrasound $2015 ; 4: 4-9$

123. Davoudi M, Colt HG, Osann KE, Lamb CR, Mullon JJ. Endobronchial ultrasound skills and tasks assessment tool: assessing the validity evidence for a test of endobronchial ultrasound-guided transbronchial needle aspiration operator skill. Am J Respir Crit Care Med 2012;186:773-9.

124. Scarlata S, Palermo $P$, Candoli P, Tofani A, Petitti T, Corbetta L. EBUSSTAT Subscore Analysis to Predict the Efficacy and Assess the Validity of Virtual Reality Simulation for EBUS-TBNA Training Among Experienced Bronchoscopists. J Bronchology Interv Pulmonol 2017;24:110-6.

125. van Hove PD, Tuijthof GJ, Verdaasdonk EG, Stassen LP, Dankelman J. Objective assessment of technical surgical skills. Br J Surg 2010;97:972-87.

126. Konge L, Annema J, Clementsen P, Minddal V, Vilmann P, Ringsted C. Using virtual-reality simulation to assess performance in endobronchial ultrasound. Respiration 2013;86:59-65.

127. Konge L, Vilmann P, Clementsen P, Annema JT, Ringsted C. Reliable and valid assessment of competence in endoscopic ultrasonography and fine-needle aspiration for mediastinal staging of non-small cell lung cancer. Endoscopy 2012;44:928-33.

Conflicts of interest.-The authors certify that there is no conflict of interest with any financial organization regarding the material discussed in the manuscript. Article first published online: November 9, 2018. - Manuscript accepted: October 30, 2018. - Manuscript received: October 17, 2018. 